\title{
MULTIPLE POSITIVE SOLUTIONS OF SINGULAR POSITONE DIRICHLET PROBLEMS WITH DERIVATIVE DEPENDENCE*
}

\author{
BAOQIANG YAN \\ Department of Mathematics, Shandong Normal University, Ji-nan, 250014, P.R. China \\ DONAL O'REGAN \\ Department of Mathematics, National University of Ireland, Galway, Ireland \\ and RAVI P. AGARWAL \\ Department of Mathematical Science, Florida Institute of Technology, Melbourne, Florida 32901, USA
}

(Received 4 November, 2005; revised 3 February, 2006; accepted 10 March, 2006)

Abstract. The existence of multiple positive solutions is presented for the singular Dirichlet boundary value problems

$$
\left\{\begin{array}{l}
x^{\prime \prime}+\Phi(t) f\left(t, x(t),\left|x^{\prime}(t)\right|\right)=0, \\
x(0)=0, \quad x(1)=0,
\end{array}\right.
$$

using the fixed point index; here $f$ may be singular at $x=0$ and $x^{\prime}=0$.

1. Introduction. In [11], S. Staněk considered

$$
\left\{\begin{array}{l}
x^{\prime \prime}+\mu q(t) f\left(t, x, x^{\prime}\right)=0, \\
x(0)=0, x(T)=0,
\end{array}\right.
$$

where $q(t)>0$ for $t \in[0, T], A>0$ is a constant and $f\left(t, x, x^{\prime}\right)>0$ is continuous on $[0, T] \times(0,+\infty) \times\left[-\frac{2 A}{T}, 0\right) \cup\left(0, \frac{2 A}{T}\right]$ and may be singular at $x=0, x=A$ and $x^{\prime}=0$. Now $x$ is a solution of the above equation if $x(0)=x(T)=0$ and $x$ satisfies $x^{\prime \prime}(t)+$ $\mu q(t) f\left(t, x(t), x^{\prime}(t)\right)=0$ for all $t \in\left\{t \in(0, T): x^{\prime}(t) \neq 0\right\}$. Existence of one solution was established in [11] using regularity and sequential techniques. In [1] existence of the above equation was established when $f$ was singular at $x=0$ but not at $x^{\prime}=0$. However in [1] $f$ was allowed to change sign. Various other existence results for $x^{\prime \prime}+f\left(t, x, x^{\prime}\right)=$ 0 were established [7, 9-11] when $f$ is singular at $x^{\prime}=0$. If $f\left(t, x, x^{\prime}\right)=f(t, x)$ is singular at $x=0$ there are many results on the existence of multiple positive solutions to $x^{\prime \prime}+f(t, x)=0$ (see [2-4], [11]). However to date there are only a few results [6, 12] on the existence of multiple solutions to $x^{\prime \prime}+f\left(t, x,\left|x^{\prime}\right|\right)=0$ when $f$ has a derivative dependence. The goal of this paper is to attempt to fill this gap in the literature.

\footnotetext{
* The project is supported by the fund of National Nature Science (10571111) and the fund of Natural Science of Shandong Province (Y2005A07).
} 
In this paper we consider the singular Dirichlet boundary value problems

$$
\left\{\begin{array}{l}
x^{\prime \prime}+\Phi(t) f\left(t, x,\left|x^{\prime}\right|\right)=0, \\
x(0)=0, x(1)=0,
\end{array}\right.
$$

where $f$ may be singular at $x=0$ and $x^{\prime}=0$. The definition of a solution to (1.1) is as above (as in [11]). There are main three sections in our paper. In Section 2, we define a special Banach space, construct a special cone in it and give its properties. In Section 3, using the theory of fixed point index, we present a new result on the existence of multiple solutions to (1.1) when $f$ is singular at $x^{\prime}=0$ and not singular at $x=0$. In Section 4 when $f$ is singular at $x=0$ and $x^{\prime}=0$ we establish the existence of multiple positive solutions to (1.1).

2. Preliminaries. Let $q(t)=t(1-t), t \in[0,1]$ and $C_{q}^{1}[0,1]=\{x:[0,1] \rightarrow R \mid x$ is continuous on $[0,1]$ and continuously differentiable on $(0,1)$ with $\sup _{t \in(0,1)} q(t)\left|x^{\prime}(t)\right|=$ $\left.\sup _{t \in(0,1)} t(1-t)\left|x^{\prime}(t)\right|<+\infty\right\}$. For $x \in C_{q}^{1}[0,1]$, define $\|x\|=\max \left\{\|x\|_{1},\|x\|_{2}\right\}$, where $\|x\|_{1}=\max _{t \in[0,1]}|x(t)|$ and $\|x\|_{2}=\sup _{t \in(0,1)} t(1-t)\left|x^{\prime}(t)\right|$.

Lemma 2.1. $C_{q}^{1}[0,1]$ is a Banach space. For any $x \in C_{q}^{1}[0,1],\left|x^{\prime}(t)\right| \leq \frac{\|x\|}{t(1-t)}, t \in$ $(0,1)$.

Proof. Clearly $C_{q}^{1}[0,1]$ is a linear space with zero element $\theta(t) \equiv 0$ for $t \in[0,1]$ and it is also easy to check that $\|\cdot\|$ is a norm on $C_{q}^{1}[0,1]$.

We show that $C_{q}^{1}[0,1]$ is complete. Assume $\left\{x_{n}\right\}_{n=1}^{\infty} \subseteq C_{q}^{1}[0,1]$ is a Cauchy sequence, i.e., for any $\varepsilon>0$, there exists an $N>0$ such that $\left\|x_{n}-x_{m}\right\|<\varepsilon$ for all $n>N, m>N$. Since $\left\|x_{n}-x_{m}\right\|_{1} \leq\left\|x_{n}-x_{m}\right\|,\left\{x_{n}\right\} \subseteq C[0,1]$ is a Cauchy sequence with

$$
\lim _{n \rightarrow+\infty}\left\|x_{n}-x_{0}\right\|_{1}=0, x_{0} \in C[0,1] \text {. }
$$

Also for any given $\delta>0$, one has

$$
\begin{aligned}
& \delta(1-\delta) \max _{t \in[\delta, 1-\delta]}\left|x_{n}^{\prime}(t)-x_{m}^{\prime}(t)\right| \leq \max _{t \in[\delta, 1-\delta]} t(1-t)\left|x_{n}^{\prime}(t)-x_{m}^{\prime}(t)\right| \\
& \quad \leq \sup _{t \in(0,1)} t(1-t)\left|x_{n}^{\prime}(t)-x_{m}^{\prime}(t)\right|=\left\|x_{n}-x_{m}\right\|_{2} \leq\left\|x_{n}-x_{m}\right\|
\end{aligned}
$$

which means $\max _{t \in[\delta, 1-\delta]}\left|x_{n}^{\prime}(t)-x_{m}^{\prime}(t)\right| \leq \frac{1}{\delta(1-\delta)}\left\|x_{n}-x_{m}\right\|, \forall n>N, m>N$.

Consequently, $x_{0}$ is continuously differentiable on $[\delta, 1-\delta]$ with $\lim _{n \rightarrow+\infty} x_{n}^{\prime}(t)=$ $x_{0}^{\prime}(t)$ uniformly on $[\delta, 1-\delta]$. Since $\delta$ is arbitrary, $x_{0}$ is continuously differentiable on $(0,1)$. Now $\sup _{t \in(0,1)} t(1-t)\left|x_{n}^{\prime}(t)-x_{m}^{\prime}(t)\right| \leq\left\|x_{n}-x_{m}\right\|<\varepsilon$, so letting $m \rightarrow+\infty$ yields

$$
\sup _{t \in(0,1)} t(1-t)\left|x_{n}^{\prime}(t)-x_{0}^{\prime}(t)\right| \leq \varepsilon
$$

Also from (2.1) and (2.2), one has $\lim _{n \rightarrow+\infty}\left\|x_{n}-x_{0}\right\|=0$.

Finally from (2.2), it is easy to see that $x_{0} \in C_{q}^{1}[0,1]$. Hence, $C_{q}^{1}[0,1]$ is a Banach space. If $x \in C_{q}^{1}[0,1]$, then $\sup _{t \in(0,1)} t(1-t)\left|x^{\prime}(t)\right|=\|x\|_{2} \leq\|x\|$, which means $\left|x^{\prime}(t)\right| \leq$ $\frac{\|x\|}{t(1-t)}$ for all $t \in(0,1)$. 
Let

$$
G(t, s)=\left\{\begin{array}{l}
(1-t) s, 0 \leq s \leq t \leq 1 \\
t(1-s), 0 \leq t \leq s \leq 1
\end{array}\right.
$$

and

$$
P=\left\{x \in C_{q}^{1}[0,1]: x(t) \geq t(1-t)\|x\|_{1}, \forall t \in[0,1] \text { and } x\left(\frac{1}{2}\right) \geq \frac{1}{4}\|x\|_{2}\right\} .
$$

The following lemmas are needed in Section 3 and Section 4.

Lemma 2.2 (see [5]). Let $\Omega$ be a bounded open set in real Banach space $E, P$ be a cone of $E, \theta \in \Omega$ and $A: \bar{\Omega} \cap P \rightarrow P$ be continuous and compact. Suppose that $\lambda A x \neq x, \forall x \in \partial \Omega \cap P, \lambda \in(0,1]$. Then

$$
i(A, \Omega \cap P, P)=1 .
$$

LEMMA 2.3 (see [5]). Let $\Omega$ be a bounded open set in real Banach space $E, P$ be a cone of $E, \theta \in \Omega$ and $A: \bar{\Omega} \cap P \rightarrow P$ be continuous and compact. Suppose that $A x \not \leq x, \forall x \in \partial \Omega \cap P$. Then

$$
i(A, \Omega \cap P, P)=0 .
$$

LEMMA 2.4. If $x \in P$ (defined as in (2.4)), then $\|x\| \leq 4\|x\|_{1}$.

Proof. If $x \in P$, one has $\|x\|_{1}=\max \{|x(t)|: t \in[0,1]\} \geq x\left(\frac{1}{2}\right) \geq \frac{1}{4}\|x\|_{2}$. Then $\|x\|=\max \left\{\|x\|_{1},\|x\|_{2}\right\} \leq \max \left\{\|x\|_{1}, 4 x\left(\frac{1}{2}\right)\right\} \leq \max \left\{\|x\|_{1}, 4\|x\|_{1}\right\}=4\|x\|_{1}$.

Lemma 2.5. Assume that $\bar{\Phi} \in C\left((0,1), R^{+}\right)$with $\int_{0}^{1} \bar{\Phi}(t) d t<\infty$ and let $F(t)=$ $\int_{0}^{1} G(t, s) \bar{\Phi}(s) d s$. Then

$$
\left\{\begin{array}{l}
F(t) \geq t(1-t) \max _{s \in[0,1]} F(s)=q(t)\|F\|_{1}, \quad \forall t \in[0,1] \\
\|F\|_{2} \leq\|F\|_{1} \\
\|F\|_{2}=\sup _{t \in(0,1)} q(t)\left|F^{\prime}(t)\right| \leq 4 F\left(\frac{1}{2}\right)
\end{array}\right.
$$

i.e., $F \in P$.

Proof. Assume that $F(\tau)=\max _{t \in[0,1]} F(t)=\|F\|_{1}$. For $t \in[0,1]$, we have

$$
\frac{G(t, s)}{G(\tau, s)}=\left\{\begin{array}{ll}
\frac{t(1-s)}{(1-\tau) s}=t(1-t) \frac{(1-s)}{(1-\tau)} \frac{1}{(1-t) s} \geq t(1-t), & t \leq s \leq \tau \\
\frac{(1-t) s}{\tau(1-s)}=t(1-t) \frac{s}{\tau} \frac{1}{t(1-s)} \geq t(1-t), & \tau \leq s \leq t \\
\frac{t(1-s)}{\tau(1-s)}=t(1-t) \frac{1}{\tau(1-t)} \geq t(1-t), & t, \tau \leq s \\
\frac{(1-t) s}{(1-\tau) s}=t(1-t) \frac{1}{t(1-\tau)} \geq t(1-t), & t, \tau \geq s
\end{array}=q(t), \quad t \in[0,1] .\right.
$$

Then, for $t \in[0,1]$, we have

$$
\begin{aligned}
F(t) & =\int_{0}^{1} G(t, s) \bar{\Phi}(s) d s=\int_{0}^{1} \frac{G(t, s)}{G(\tau, s)} G(\tau, s) \bar{\Phi}(s) d s \\
& \geq t(1-t) \int_{0}^{1} G(\tau, s) \bar{\Phi}(s) d s=t(1-t) F(\tau)=t(1-t)\|F\|_{1},
\end{aligned}
$$


which implies that

$$
F\left(\frac{1}{2}\right) \geq \frac{1}{2}\left(1-\frac{1}{2}\right)\|F\|_{1}=\frac{1}{4}\|F\|_{1}, \quad \text { i.e., } \quad\|F\|_{1} \leq 4 F\left(\frac{1}{2}\right) .
$$

Moreover, since $F^{\prime}(t)=-\int_{0}^{t} s \bar{\Phi}(s) d s+\int_{t}^{1}(1-s) \bar{\Phi}(s) d s$ for all $t \in[0,1]$ and $F(t) \geq 0$, one has

$$
\begin{aligned}
t(1-t)\left|F^{\prime}(t)\right| & \leq t(1-t) \int_{0}^{t} s \bar{\Phi}(s) d s+(1-t) t \int_{t}^{1}(1-s) \bar{\Phi}(s) d s \\
& \leq(1-t) \int_{0}^{t} s \bar{\Phi}(s) d s+t \int_{t}^{1}(1-s) \bar{\Phi}(s) d s \\
& =\int_{0}^{1} G(t, s) \bar{\Phi}(s) d s \leq\|F\|_{1} \leq 4 F\left(\frac{1}{2}\right), \quad t \in[0,1],
\end{aligned}
$$

which means that $\|F\|_{2}=\sup _{t \in(0,1)} t(1-t)\left|F^{\prime}(t)\right| \leq\|F\|_{1} \leq 4 F\left(\frac{1}{2}\right)$. Consequently, $F \in P$.

Now we list some conditions which will be needed in Sections 3 and 4:

$$
\Phi \in C[0,1] \text { with } \Phi(t)>0 \text { on }(0,1),
$$

and

$$
\left\{\begin{array}{l}
f:[0,1] \times[0,+\infty) \times[0,+\infty) \rightarrow[0,+\infty) \text { is continuous with } \\
f(t, x, y)>0 \text { for }(t, x, y) \in[0,1] \times[0,+\infty) \times[0,+\infty) \\
f(t, x, y) \leq[h(x)+w(x)][g(y)+r(y)] \\
\text { on }[0,1] \times[0,+\infty) \times[0,+\infty) \text { with } w>0, g>0 \\
\text { continuous and nonincreasing on }[0,+\infty), \\
\int_{0}^{1} \Phi(s) r\left(k_{0} \frac{1}{s(1-s)}\right) d s<+\infty, \text { for all } k_{0}>0, \text { and } \\
h \geq 0, \quad r \geq 0 \text { continuous and nondecreasing on }[0, \infty) .
\end{array}\right.
$$

For $x \in P$, define an operator by

$$
(A x)(t)=\int_{0}^{1} G(t, s) \Phi(s) f\left(s, x(s),\left|x^{\prime}(s)\right|\right) d s, \quad t \in[0,1] .
$$

Lemma 2.6. Assume that (2.9) and (2.10) hold. Then $A: P \rightarrow P$ is continuous and completely continuous. Moreover, for every $x \in P, A x \in C^{1}[0,1]$.

Proof. First, we show that $A: P \rightarrow P$ is well defined and $A x \in C^{1}[0,1]$ for each $x \in P$. For $x \in P$, Lemma 2.1 yields $\left|x^{\prime}(t)\right| \leq \frac{\|x\|}{t(1-t)}, t \in(0,1)$. Then, from (2.9) and (2.10), we have that for $t \in[0,1]$,

$$
\begin{aligned}
|(A x)(t)| & =\left|\int_{0}^{1} G(t, s) \Phi(s) f\left(s, x(s),\left|x^{\prime}(s)\right|\right) d s\right| \\
& \leq \int_{0}^{1} G(t, s) \Phi(s)[h(x(s))+w(x(s))]\left[g\left(\left|x^{\prime}(s)\right|\right)+r\left(\left|x^{\prime}(s)\right|\right)\right] d s \\
& \leq \int_{0}^{1} G(t, s) \Phi(s)[h(\|x\|)+w(0)]\left[g(0)+r\left(\frac{\|x\|}{s(1-s)}\right)\right] d s<+\infty
\end{aligned}
$$


and

$$
\begin{aligned}
\left|(A x)^{\prime}(t)\right| & =\left|-\int_{0}^{t} s \Phi(s) f\left(s, x(s),\left|x^{\prime}(s)\right|\right) d s+\int_{t}^{1}(1-s) \Phi(s) f\left(s, x(s),\left|x^{\prime}(s)\right|\right) d s\right| \\
& \leq \int_{0}^{1} \Phi(s)\left|f\left(s, x(s),\left|x^{\prime}(s)\right|\right)\right| d s \\
& \leq \int_{0}^{1} \Phi(s)[h(\|x\|)+w(0)]\left[g(0)+r\left(\frac{\|x\|}{s(1-s)}\right)\right] d s<+\infty, \quad t \in[0,1],
\end{aligned}
$$

which means that $A$ is well defined. From Lemma 2.5, for every $x \in P$, we have $A x \in P$, which implies that $A P \subseteq P$. Moreover, since

$$
\begin{aligned}
& \left|(A x)^{\prime}\left(t_{1}\right)-(A x)^{\prime}\left(t_{2}\right)\right| \\
& \leq\left|\int_{t_{1}}^{1}(1-s) \Phi(s) f\left(s, x(s),\left|x^{\prime}(s)\right|\right) d s-\int_{t_{2}}^{1}(1-s) \Phi(s) f\left(s, x(s),\left|x^{\prime}(s)\right|\right) d s\right| \\
& \quad+\left|-\int_{0}^{t_{1}} s \Phi(s) f\left(s, x(s),\left|x^{\prime}(s)\right|\right) d s+\int_{0}^{t_{2}} s \Phi(s) f\left(s, x(s),\left|x^{\prime}(s)\right|\right) d s\right| \\
& \leq 2\left|\int_{t_{1}}^{t_{2}} \Phi(s)[h(\|x\|)+w(0)]\left[g(0)+r\left(\frac{\|x\|}{s(1-s)}\right)\right] d s\right|,
\end{aligned}
$$

we see that $\lim _{t \rightarrow 0+}(A x)^{\prime}(t)$ exists and $\lim _{t \rightarrow 1-}(A x)^{\prime}(t)$ exists, which means that $A x \in$ $C^{1}[0,1]$.

Now we show that $A: P \rightarrow P$ is continuous. Assume that $\left\{x_{m}\right\}_{m=1}^{\infty} \subseteq P$ and $x_{0} \in$ $P$ with $\lim _{m \rightarrow+\infty} x_{m}=x_{0}$. Then, there exists an $M>0$ such that $\left\|x_{m}\right\|<M$ for all $m \in\{1,2, \ldots\}$ (note that Lemma 2.1 guarantees that $\left|x_{m}^{\prime}(t)\right| \leq \frac{M}{t(1-t)}, \forall t \in(0,1)$ ). Thus, $\lim _{m \rightarrow+\infty} f\left(t, x_{m}(t),\left|x_{m}^{\prime}(t)\right|\right)=f\left(t, x_{0}(t),\left|x_{0}^{\prime}(t)\right|\right), \quad t \in(0,1)$ and

$$
\left|f\left(t, x_{m}(t),\left|x_{m}^{\prime}(t)\right|\right)\right| \leq[h(M)+w(0)]\left[g(0)+r\left(\frac{M}{t(1-t)}\right)\right] .
$$

The Lebesgue Dominated Convergence Theorem guarantees that

$$
\begin{aligned}
& \left\|A x_{m}-A x_{0}\right\|_{1} \\
& \quad=\max _{t \in[0,1]}\left|\int_{0}^{1} G(t, s) \Phi(s)\left[f\left(s, x_{m}(s),\left|x_{m}^{\prime}(s)\right|\right)-f\left(s, x_{0}(s),\left|x_{0}^{\prime}(s)\right|\right)\right] d s\right| \\
& \quad \leq \int_{0}^{1} \Phi(s)\left|f\left(s, x_{m}(s),\left|x_{m}^{\prime}(s)\right|\right)-f\left(s, x_{0}(s),\left|x_{0}^{\prime}(s)\right|\right)\right| d s \rightarrow 0, \text { as } m \rightarrow+\infty
\end{aligned}
$$

and

$$
\begin{aligned}
& \left\|A x_{m}-A x_{0}\right\|_{2} \\
& =\sup _{t \in(0,1)} t(1-t) \mid-\int_{0}^{t} s \Phi(s)\left[f\left(s, x_{m}(s),\left|x_{m}^{\prime}(s)\right|\right)-f\left(s, x_{0}(s),\left|x_{0}^{\prime}(s)\right|\right)\right] d s \\
& \quad+\int_{t}^{1}(1-s) \Phi(s)\left[f\left(s, x_{m}(s),\left|x_{m}^{\prime}(s)\right|\right)-f\left(s, x_{0}(s),\left|x_{0}^{\prime}(s)\right|\right)\right] d s \mid \\
& \leq \int_{0}^{1} \Phi(s)\left|f\left(s, x_{m}(s),\left|x_{m}^{\prime}(s)\right|\right)-f\left(s, x_{0}(s),\left|x_{0}^{\prime}(s)\right|\right)\right| d s \rightarrow 0, \text { as } m \rightarrow+\infty,
\end{aligned}
$$

which implies that $\lim _{m \rightarrow+\infty}\left\|A x_{m}-A x_{0}\right\|=0$. Hence, $A: P \rightarrow P$ is continuous. 
Finally we show for any bounded $D \subseteq P, A(D)$ is relatively compact. Since $D$ is bounded, there exists an $M>0$ such that $\|x\| \leq M$ for all $x \in D$ (note that Lemma 2.1 guarantees that $\left.\left|x^{\prime}(t)\right| \leq \frac{M}{t(1-t)}, \forall t \in(0,1)\right)$. Now (2.9) and (2.10) yield

$$
\begin{aligned}
\|A x\|_{1} & =\max _{t \in[0,1]}\left|\int_{0}^{1} G(t, s) \Phi(s) f\left(s, x(s),\left|x^{\prime}(s)\right|\right) d s\right| \\
& \leq \int_{0}^{1} \Phi(s)[h(x(s))+w(x(s))]\left[g\left(\left|x^{\prime}(s)\right|\right)+r\left(\left|x^{\prime}(s)\right|\right)\right] d s \\
& \leq \int_{0}^{1} \Phi(s)[h(M)+w(0)]\left[g(0)+r\left(\frac{M}{s(1-s)}\right)\right] d s
\end{aligned}
$$

which implies that the functions belonging to $\{(A D)(t)\}$ are uniformly bounded on $[0,1]$, and

$$
\begin{aligned}
& \sup _{t \in(0,1)}\left|(A x)^{\prime}(t)\right| \\
& \quad=\sup _{t \in[0,1]}\left|-\int_{0}^{t} s \Phi(s) f\left(s, x(s),\left|x^{\prime}(s)\right|\right) d s+\int_{t}^{1}(1-s) \Phi(s) f\left(s, x(s),\left|x^{\prime}(s)\right|\right) d s\right| \\
& \leq \int_{0}^{1} \Phi(s)[h(x(s))+w(x(s))]\left[g\left(\left|x^{\prime}(s)\right|\right)+r\left(\left|x^{\prime}(s)\right|\right)\right] d s \\
& \leq \int_{0}^{1} \Phi(s)[h(M)+w(0)]\left[g(0)+r\left(\frac{M}{s(1-s)}\right)\right] d s .
\end{aligned}
$$

which implies that the functions belonging to $\left\{(A D)^{\prime}(t)\right\}$ are uniformly bounded on $[0,1]$ and the functions belonging to $\{(A D)(t)\}$ are equicontinuous on $[0,1]$.

For any $t_{1}, t_{2} \in[0,1], x \in D$, we have

$$
\begin{aligned}
& \left|(A x)^{\prime}\left(t_{1}\right)-(A x)^{\prime}\left(t_{2}\right)\right| \\
& =\mid-\int_{0}^{t_{1}} s \Phi(s) f\left(s, x(s),\left|x^{\prime}(s)\right|\right) d s+\int_{0}^{t_{2}} s \Phi(s) f\left(s, x(s),\left|x^{\prime}(s)\right|\right) d s \\
& \quad+\int_{t_{1}}^{1}(1-s) \Phi(s) f\left(s, x(s),\left|x^{\prime}(s)\right|\right) d s-\int_{t_{2}}^{1}(1-s) \Phi(s) f\left(s, x(s),\left|x^{\prime}(s)\right|\right) d s \mid \\
& \leq 2\left|\int_{t_{1}}^{t_{2}} \Phi(s)[h(M)+w(0)]\left[g(0)+r\left(\frac{M}{s(1-s)}\right)\right] d s\right| .
\end{aligned}
$$

Therefore, for any $\varepsilon>0$, there exists a $\delta>0$ such that $\left|(A x)^{\prime}\left(t_{1}\right)-(A x)^{\prime}\left(t_{2}\right)\right|<$ $\varepsilon, \forall\left|t_{1}-t_{2}\right|<\delta, \quad x \in D$, which means that the functions from $\left\{(A x)^{\prime}(t), x \in D\right\}$ are equicontinuous on $[0,1]$.

By the Arzela-Ascoli theorem, $A(D)$ is relatively compact under the ordinary norm $\|A x\|_{0}=\max \left\{\max \{|(A x)(t)|, t \in[0,1]\}, \max \left\{\left|(A x)^{\prime}(t)\right|, t \in[0,1]\right\}\right\}$. Since the new norm $\|A x\|$ is less than the ordinary norm $\|A x\|_{0}$, we know that $A D$ is relatively compact under the new norm $\|\cdot\|$.

Hence, $A: P \rightarrow P$ is continuous and completely continuous.

3. Multiple positive solutions to (1.1) with singularity at $x^{\prime}=0$ but not at $x=0$. In this section our nonlinearity $f$ may be singular at $x^{\prime}=0$ but not at $x=0$. Throughout 
this section we will assume that the following conditions hold:

$$
\Phi \in C[0,1] \text { with } \Phi(t)>0 \text { on }(0,1),
$$

$\left\{\begin{array}{l}f:[0,1] \times[0,+\infty) \times(0,+\infty) \rightarrow(0,+\infty) \text { is continuous with } \\ f(t, x, y)>0 \text { for }(t, x, y) \in[0,1] \times[0,+\infty) \times(0,+\infty), \\ f(t, x, y) \leq h(x)[g(y)+r(y)] \text { on }[0,1] \times[0,+\infty) \times(0,+\infty) \text { with } \\ \int_{0}^{1} \Phi(s) r\left(k_{0} \frac{1}{s(1-s)}\right) d s<+\infty, \quad \text { for all } k_{0}>0, \text { and } \\ h \geq 0, r \geq 0 \text { continuous and nondecreasing on }[0, \infty) \\ g>0 \text { continuous and nonincreasing on }(0, \infty),\end{array}\right.$

$$
\left\{\begin{array}{l}
\sup _{c \in(0,+\infty)} \frac{c}{I^{-1}\left(h(c) \int_{0}^{1} \Phi(s) d s\right)}>1 \\
\text { where } I(z)=\int_{0}^{z} \frac{1}{g(u)+r(u)} d u, z \in(0,+\infty)
\end{array}\right.
$$

$\left\{\begin{array}{l}\text { for constants } H, H^{\prime}>0 \text { there exists a function } \psi_{H, H^{\prime}} \\ \text { continuous on }[0,1] \text { and positive on }(0,1) \\ \text { and a positive constant } 0 \leq \gamma<1 \text { such that } \\ f(t, x, y) \geq \psi_{H}(t) x^{\gamma} \text { on }[0,1] \times[0, H] \times\left(0, H^{\prime}\right]\end{array}\right.$

and

$$
\left\{\begin{array}{l}
\text { there exists a } g_{1} \in C([0,+\infty) \times(0,+\infty),(0,+\infty)) \text { with } \\
f(t, x, y) \geq g_{1}(x, y), \forall(t, x, y) \in[0,1] \times[0,+\infty) \times(0,+\infty) \text { such that } \\
\lim _{x \rightarrow+\infty} \frac{g_{1}(x, y)}{x}=+\infty \text { uniformly for } y \in(0,+\infty) .
\end{array}\right.
$$

THEOREM 3.1. Suppose that (3.1)-(3.5) hold. Then (1.1) has at least two nonnegative solutions $x_{0,1}, x_{0,2} \in C^{1}[0,1] \cap C^{2}(0,1)$ with $x_{0,1}(t)>0$ and $x_{0,2}(t)>0$ on $(0,1)$.

Proof. From (3.3) and the continuity of $I^{-1}$ and $h$, choose an $R_{1}>0$, and a $\varepsilon>0$ with $\varepsilon<\frac{R_{1}}{2}$ and

$$
\frac{R_{1}}{I^{-1}\left(I(\varepsilon)+h\left(R_{1}+\varepsilon\right) \int_{0}^{1} \Phi(s) d s\right)}>1
$$

Let $n_{0} \in\{1,2, \ldots\}$ be chosen so that $\frac{1}{n_{0}}<\varepsilon$, and let $N_{0}=\left\{n_{0}, n_{0}+1, \ldots\right\}$. For each $n \in N_{0}$, for $x \in P$, define

$$
\left(A_{n} x\right)(t)=\int_{0}^{1} G(t, s) \Phi(s) f\left(s, x(s)+\frac{1}{n} s,\left|x^{\prime}(s)\right|+\frac{1}{n}\right) d s, \quad t \in[0,1] .
$$

It is easy to see that $f\left(t, x+\frac{1}{n} t,\left|x^{\prime}\right|+\frac{1}{n}\right) \leq h\left(x+\frac{1}{n}\right)\left[g\left(\frac{1}{n}\right)+r\left(\left|x^{\prime}\right|+\frac{1}{n}\right)\right], \quad\left(t, x, x^{\prime}\right) \in$ $[0,1] \times[0,+\infty) \times[0,+\infty)$. Now (3.2) implies that (2.10) is true for each $n \in N_{0}$. Then, Lemma 2.6 guarantees that $A_{n}: P \rightarrow P$ is continuous and completely continuous with $A_{n} P \subseteq C^{1}[0,1]$ for each $n \in N_{0}$.

Let

$$
\Omega_{1}=\left\{x \in C_{q}^{1}[0,1]:\|x\|<R_{1}\right\}
$$


Choose $0<a^{*}<b^{*}<1$ and let

$$
N^{*}=\left(a^{*}\left(1-b^{*}\right) \frac{1}{4} \min _{t \in\left[a^{*}, b^{*}\right]} \int_{a^{*}}^{b^{*}} G(t, s) \Phi(s) d s\right)^{-1}+1 .
$$

Now from (3.5), there exists an $R_{2}>R_{1}$ such that

$$
g_{1}(x, y) \geq N^{*} x, \quad \forall x \geq R_{2}, y \in(0,+\infty) .
$$

Let

$$
\Omega_{2}=\left\{x \in C_{q}^{1}[0,1]:\|x\|<\frac{4 R_{2}}{a^{*}\left(1-b^{*}\right)}\right\} .
$$

Then, for each $n \in N_{0}$, we claim that

$$
\mu A_{n} x \neq x, \quad \forall \mu \in(0,1], \quad x \in P \cap \partial \Omega_{1},
$$

and

$$
A_{n} x \not \leq x, \quad \forall x \in P \cap \partial \Omega_{2} .
$$

First we show that (3.10) is true. Suppose there exists an $x_{0} \in P \cap \partial \Omega_{1}$ and a $\mu_{0} \in(0,1]$ such that $x_{0}=\mu_{0} A_{n} x_{0}$. Then

$x_{0}^{\prime \prime}(t)+\mu_{0} \Phi(t) f\left(t, x_{0}(t)+\frac{1}{n} t,\left|x_{0}^{\prime}(t)\right|+\frac{1}{n}\right)=0, t \in(0,1)$, and $x_{0}(0)=0, x_{0}(1)=0$,

which means that $x_{0}(t)>0$ on $(0,1)$ with $x_{0}(0)=x_{0}(1)=0$ and $x_{0}^{\prime}(t)$ is decreasing on $(0,1)$. Thus, there exists a unique $t_{0} \in(0,1)$ with $x_{0}^{\prime}\left(t_{0}\right)=0, x_{0}^{\prime}(t)>0$ on $\left(0, t_{0}\right)$ and $x_{0}^{\prime}(t)<0$ on $\left(t_{0}, 1\right)$ and $\left\|x_{0}\right\|_{1}=x_{0}\left(t_{0}\right)$. From (3.2), we have

$$
-x_{0}^{\prime \prime}(t) \leq \Phi(t) h\left(x_{0}(t)+\frac{1}{n} t\right)\left[g\left(x_{0}^{\prime}(t)+\frac{1}{n}\right)+r\left(x_{0}^{\prime}(t)+\frac{1}{n}\right)\right], \forall t \in\left(0, t_{0}\right),
$$

which means that

$$
\frac{-x_{0}^{\prime \prime}(t)}{g\left(x_{0}^{\prime}(t)+\frac{1}{n}\right)+r\left(x_{0}^{\prime}(t)+\frac{1}{n}\right)} \leq h\left(x_{0}(t)+\frac{1}{n} t\right) \Phi(t), \quad \forall t \in\left(0, t_{0}\right) .
$$

Integration from $t$ to $t_{0}$ yields $I\left(x_{0}^{\prime}(t)+\frac{1}{n}\right)-I\left(x_{0}^{\prime}\left(t_{0}\right)+\frac{1}{n}\right)=I\left(x_{0}^{\prime}(t)+\frac{1}{n}\right)-I\left(\frac{1}{n}\right) \leq$ $h\left(x_{0}\left(t_{0}\right)+\frac{1}{n}\right) \int_{0}^{1} \Phi(s) d s$, i.e., $I\left(x_{0}^{\prime}(t)+\frac{1}{n}\right)<I(\varepsilon)+h\left(R_{1}+\varepsilon\right) \int_{0}^{1} \Phi(s) d s$. Then,

$$
x_{0}^{\prime}(t)<x_{0}^{\prime}(t)+\frac{1}{n}<I^{-1}\left(I(\varepsilon)+h\left(R_{1}+\varepsilon\right) \int_{0}^{1} \Phi(s) d s\right), \forall t \in\left(0, t_{0}\right] .
$$

Now integrate from 0 to $t_{0}$ to obtain

$$
\left\|x_{0}\right\|_{1}=x_{0}\left(t_{0}\right)=x_{0}\left(t_{0}\right)-x_{0}(0) \leq I^{-1}\left(I(\varepsilon)+h\left(R_{1}+\varepsilon\right) \int_{0}^{1} \Phi(s) d s\right) .
$$


Similarly, if $t>t_{0}$, we have

$$
\frac{-x_{0}^{\prime \prime}(t)}{g\left(-x_{0}^{\prime}(t)+\frac{1}{n}\right)+r\left(-x_{0}^{\prime}(t)+\frac{1}{n}\right)} \leq h\left(x_{0}(t)+\frac{1}{n} t\right) \Phi(t),
$$

and $\quad I\left(-x_{0}^{\prime}(t)+\frac{1}{n}\right)-I\left(-x_{0}^{\prime}\left(t_{0}\right)+\frac{1}{n}\right)=I\left(-x_{0}^{\prime}(t)+\frac{1}{n}\right)-I\left(\frac{1}{n}\right) \leq \int_{0}^{1} \Phi(s) d s h\left(R_{1}+\varepsilon\right)$, which implies

$$
-x_{0}^{\prime}(t) \leq I^{-1}\left(I(\varepsilon)+h\left(R_{1}+\varepsilon\right) \int_{0}^{1} \Phi(s) d s\right), \quad t \in\left(t_{0}, 1\right) .
$$

Now (3.13) and (3.16) guarantee that

$$
\left\|x_{0}\right\|_{2}=\sup _{t \in(0,1)} t(1-t)\left|x^{\prime}(t)\right| \leq I^{-1}\left(I(\varepsilon)+h\left(R_{1}+\varepsilon\right) \int_{0}^{1} \Phi(s) d s\right) .
$$

Combining with (3.14) one has $R_{1}=\max \left\{\left\|x_{0}\right\|_{1},\left\|x_{0}\right\|_{2}\right\} \leq I^{-1}\left(I(\varepsilon)+h\left(R_{1}+\right.\right.$ $\left.\varepsilon) \int_{0}^{1} \Phi(s) d s\right)$, which means

$$
\frac{R_{1}}{I^{-1}\left(I(\varepsilon)+h\left(R_{1}+\varepsilon\right) \int_{0}^{1} \Phi(s) d s\right)} \leq 1
$$

a contradiction to (3.6). Then, (3.10) is true.

Next we show that (3.11) is true. Suppose that there is an $x_{0} \in P \cap \partial \Omega_{2}$ with $x_{0} \geq$ $A_{n} x_{0}$. By the definition of the cone and Lemma 2.4, one has $x_{0}(t) \geq t(1-t)\left\|x_{0}\right\|_{1} \geq$ $a^{*}\left(1-b^{*}\right) \frac{1}{4}\left\|x_{0}\right\|=a^{*}\left(1-b^{*}\right) \frac{1}{4} \frac{4 R_{2}}{a^{*}\left(1-b^{*}\right)}=R_{2}, \quad \forall t \in\left[a^{*}, b^{*}\right]$. Clearly for $t \in\left[a^{*}, b^{*}\right]$, $x_{0}(t)+\frac{1}{n} t \geq R_{2}, \quad \forall t \in\left[a^{*}, b^{*}\right]$. Then, for $t \in\left[a^{*}, b^{*}\right]$, from (3.9), one has

$$
\begin{aligned}
x_{0}(t) & \geq\left(A_{n} x_{0}\right)(t) \geq \int_{a^{*}}^{b^{*}} G(t, s) \Phi(s) g_{1}\left(x_{0}(s)+\frac{1}{n} s,\left|x_{0}^{\prime}(s)\right|+\frac{1}{n}\right) d s \\
& \geq \int_{a^{*}}^{b^{*}} G(t, s) \Phi(s) N^{*}\left(x_{0}(s)+\frac{1}{n} s\right) d s \geq \int_{a^{*}}^{b^{*}} G(t, s) \Phi(s) d s N^{*} R_{2} \\
& \geq a^{*}\left(1-b^{*}\right) \frac{1}{4} \min _{t \in\left[a^{*}, b^{*}\right]} \int_{a^{*}}^{b^{*}} G(t, s) \Phi(s) d s N^{*} \frac{4 R_{2}}{a^{*}\left(1-b^{*}\right)}>\frac{4 R_{2}}{a^{*}\left(1-b^{*}\right)},
\end{aligned}
$$

which implies that $\left\|x_{0}\right\| \geq\left\|x_{0}\right\|_{1}>\frac{4 R_{2}}{a^{*}\left(1-b^{*}\right)}$, a contradiction to $x_{0} \in P \cap \partial \Omega_{2}$. Thus, (3.11) is true.

From Lemma 2.2 and Lemma 2.3, for each $n \in N_{0}$, we have

$$
i\left(A_{n}, P \cap \Omega_{1}, P\right)=1, \text { and } i\left(A_{n}, P \cap \Omega_{2}, P\right)=0,
$$

which implies that

$$
i\left(A_{n}, P \cap\left(\Omega_{2}-\bar{\Omega}_{1}\right), P\right)=-1, \quad n \in N_{0} .
$$

As a result, for each $n \in N_{0}$, there exist $x_{n, 1} \in P \cap \Omega_{1}$ and $x_{n, 2} \in P \cap\left(\Omega_{2}-\bar{\Omega}_{1}\right)$ such that $x_{n, 1}=A_{n} x_{n, 1}$ and $x_{n, 2}=A_{n} x_{n, 2}$.

Now we consider $\left\{x_{n, 1}\right\}_{n \in N_{0}}$ and $\left\{x_{n, 2}\right\}_{n \in N_{0}}$. First we show that $\left\{x_{n, 1}\right\}$ is relatively compact in $C^{1}[0,1]$. Clearly the functions belonging to $\left\{x_{n, 1}(t)\right\}$ are uniformly bounded with $\max _{t \in[0,1]}\left|x_{n, 1}(t)\right| \leq R_{1}, n \in N_{0}$. 
For each $n \in N_{0}$, one has

$$
\begin{aligned}
x_{n, 1}^{\prime \prime}(t)+\Phi(t) f\left(t, x_{n, 1}(t)+\frac{1}{n} t,\left|x_{n, 1}^{\prime}(t)\right|+\frac{1}{n}\right) & =0, t \in(0,1), \text { and } \\
x_{n, 1}(0) & =0, x_{n, 1}(1)=0,
\end{aligned}
$$

which means that $x_{n, 1}(t)>0$ on $(0,1)$ with $x_{n, 1}(0)=x_{n, 1}(1)=0$ and $x_{n, 1}^{\prime}(t)$ is decreasing on $(0,1)$. Thus, there exists a unique $t_{n} \in(0,1)$ with $x_{n, 1}^{\prime}\left(t_{n}\right)=0, x_{n, 1}^{\prime}\left(t_{n}\right)>0$ on $\left(0, t_{n}\right)$ and $x_{n, 1}^{\prime}(t)<0$ on $\left(t_{n}, 1\right)$ and $\left\|x_{n, 1}\right\|_{1}=x_{n, 1}\left(t_{n}\right)$. Following the argument used to prove (3.12) and (3.15) yields

$$
\frac{-x_{n, 1}^{\prime \prime}(t)}{g\left(\left|x_{n, 1}^{\prime}(t)\right|+\frac{1}{n}\right)+r\left(\left|x_{n, 1}^{\prime}(t)\right|+\frac{1}{n}\right)} \leq h\left(x_{n, 1}(t)+\frac{1}{n} t\right) \Phi(t), \quad \forall t \in\left(0, t_{n}\right) \cup\left(t_{n}, 1\right) .
$$

A similar argument to that used to prove (3.13) and (3.16) yields

$$
x_{n, 1}^{\prime}(t)<x_{n, 1}^{\prime}(t)+\frac{1}{n}<I^{-1}\left(I(\varepsilon)+h\left(R_{1}+\varepsilon\right) \int_{0}^{1} \Phi(s) d s\right), \forall t \in\left(0, t_{n}\right]
$$

and

$$
-x_{n, 1}^{\prime}(t)<I^{-1}\left(I(\varepsilon)+h\left(R_{1}+\varepsilon\right) \int_{0}^{1} \Phi(s) d s\right), \quad t \in\left(t_{n}, 1\right) .
$$

Now (3.20) and (3.21) guarantee that

$$
\sup _{n \geq n_{0}} \sup _{t \in(0,1)}\left|x_{n, 1}^{\prime}(t)\right| \leq I^{-1}\left(I(\varepsilon)+h\left(R_{1}+\varepsilon\right) \int_{0}^{1} \Phi(s) d s\right) .
$$

Consequently, the functions belonging to $\left\{x_{n, 1}^{\prime}(t)\right\}$ are uniformly bounded on $[0,1]$, which implies that the functions belonging to $\left\{x_{n, 1}(t)\right\}$ are equicontinuous on $[0,1]$.

Now (3.19) yields

$$
\begin{aligned}
& \left|I\left(\left|x_{n, 1}^{\prime}\left(t_{2}\right)\right|+\frac{1}{n}\right)-I\left(\left|x_{n, 1}^{\prime}\left(t_{1}\right)\right|+\frac{1}{n}\right)\right| \leq\left|\int_{t_{1}}^{t_{2}}\|\Phi\|_{1} h\left(R_{1}+\varepsilon\right) d s\right| \\
& \quad=\|\Phi\|_{1} h\left(R_{1}+\varepsilon\right)\left|t_{1}-t_{2}\right|,
\end{aligned}
$$

if $t_{2}>t_{1}>t_{n}$ and

$$
\begin{aligned}
& \left|I\left(\left|x_{n, 1}^{\prime}\left(t_{2}\right)\right|+\frac{1}{n}\right)-I\left(\left|x_{n, 1}^{\prime}\left(t_{1}\right)\right|+\frac{1}{n}\right)\right| \leq\left|\int_{t_{1}}^{t_{2}}\|\Phi\|_{1} h\left(R_{1}+\varepsilon\right) d s\right| \\
& \quad=\|\Phi\|_{1} h\left(R_{1}+\varepsilon\right)\left|t_{1}-t_{2}\right|,
\end{aligned}
$$

if $t_{2}<t_{1}<t_{n}$. 
From (3.23) and (3.24), one has

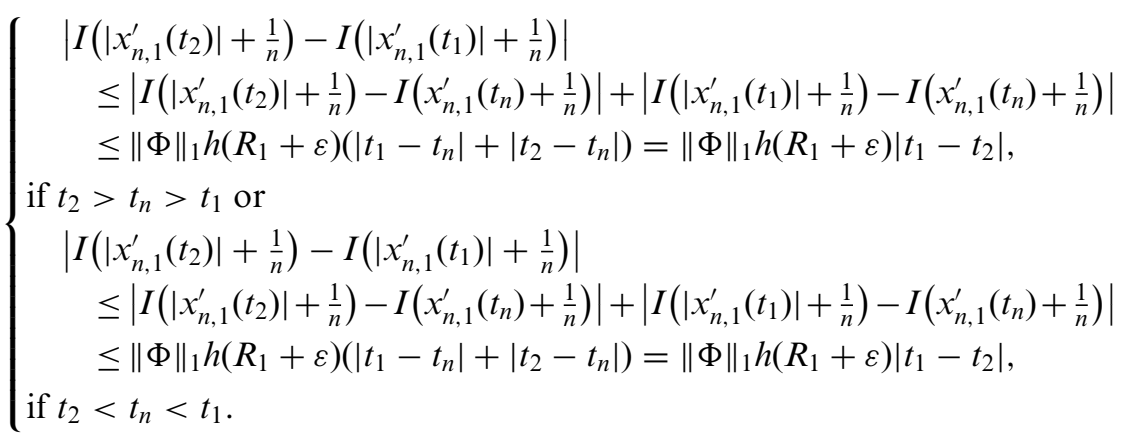

Thus, for any $\varepsilon^{\prime}>0$, there is a $\delta^{\prime}>0$ such that

$$
\left|I\left(\left|x_{n, 1}^{\prime}\left(t_{2}\right)\right|+\frac{1}{n}\right)-I\left(\left|x_{n, 1}^{\prime}\left(t_{1}\right)\right|+\frac{1}{n}\right)\right|<\varepsilon^{\prime}, \quad \forall\left|t_{2}-t_{1}\right|<\delta^{\prime}, t_{1}, t_{2} \in[0,1],
$$

which means that the functions belonging to $\left\{I\left(\left|x_{n, 1}^{\prime}(t)\right|+\frac{1}{n}\right)\right\}$ are equicontinuous on $[0,1]$. By the continuity of $I^{-1}(z)$, we know that the functions belonging to $\left\{\left|x_{n, 1}^{\prime}(t)\right|+\frac{1}{n}\right\}$ are equicontinuous on $[0,1]$, which implies the functions belonging to $\left\{\left|x_{n, 1}^{\prime}(t)\right|\right\}$ are equicontinuous on $[0,1]$. Then, for any $\varepsilon^{\prime}>0$, there is a $\delta>0$ such that $\left\|x_{n, 1}^{\prime}\left(t_{1}\right)|-| x_{n, 1}^{\prime}\left(t_{2}\right)\right\|<\varepsilon^{\prime}, \forall\left|t_{1}-t_{2}\right|<\delta, t_{1}, t_{2} \in[0,1]$, which implies $\mid x_{n, 1}^{\prime}\left(t_{1}\right)-$ $x_{n, 1}^{\prime}\left(t_{2}\right)\left|=\left\|x_{n, 1}^{\prime}\left(t_{1}\right)|-| x_{n, 1}^{\prime}\left(t_{2}\right)\right\|<\varepsilon^{\prime}, \forall\right| t_{1}-t_{2}\left|<\delta, t_{1}, t_{2} \leq t_{n} \in[0,1], \quad\right| x_{n, 1}^{\prime}\left(t_{1}\right)-$ $x_{n, 1}^{\prime}\left(t_{2}\right)\left|=\left\|x_{n, 1}^{\prime}\left(t_{1}\right)|-| x_{n, 1}^{\prime}\left(t_{2}\right)\right\|<\varepsilon^{\prime}, \forall\right| t_{1}-t_{2} \mid<\delta, t_{1}, t_{2} \geq t_{n} \in[0,1]$ and (notice $\left.x_{n, 1}^{\prime}\left(t_{n}\right)=0\right)$

$$
\begin{aligned}
\left|x_{n, 1}^{\prime}\left(t_{1}\right)-x_{n, 1}^{\prime}\left(t_{2}\right)\right| & \leq\left|x_{n, 1}^{\prime}\left(t_{1}\right)-x_{n, 1}^{\prime}\left(t_{n}\right)\right|+\left|x_{n, 1}^{\prime}\left(t_{n}\right)-x_{n, 1}^{\prime}\left(t_{2}\right)\right| \\
& =\left\|x_{n, 1}^{\prime}\left(t_{1}\right)|-| x_{n, 1}^{\prime}\left(t_{n}\right)\right\|+\left\|x_{n, 1}^{\prime}\left(t_{n}\right)|-| x_{n, 1}^{\prime}\left(t_{2}\right)\right\| \\
& <2 \varepsilon^{\prime}, \forall\left|t_{1}-t_{2}\right|<\delta, \quad t_{1}<t_{n}<t_{2} \in[0,1], \text { or } t_{2}<t_{n}<t_{1} \in[0,1],
\end{aligned}
$$

which means that the functions belonging to $\left\{x_{n, 1}^{\prime}(t)\right\}$ are equicontinuous on $[0,1]$.

Consequently, the Arzela-Ascoli Theorem guarantees that $\left\{x_{n, 1}\right\}$ is relatively compact in $C^{1}[0,1]$, which means that there is a convergent subsequence $\left\{x_{n_{j}, 1}\right\}$ of $\left\{x_{n, 1}\right\}$ such that $\lim _{j \rightarrow+\infty} x_{n_{j}, 1}=x_{0,1} \in C^{1}[0,1]$ (under the ordinary norm $\|x\|_{0}=$ $\left.\max \left\{\max _{t \in[0,1]}|x(t)|, \max _{t \in[0,1]}\left|x^{\prime}(t)\right|\right\}\right)$. Also recall that $x_{n_{j}, 1}^{\prime}\left(t_{n_{j}}\right)=0$ and $x_{n_{j}, 1}^{\prime}(t) \neq 0$ if $t \neq t_{n_{j}}$. Without loss of generality, we assume that $t_{n_{j}} \rightarrow t_{0} \in[0,1]$. Clearly $x_{0,1}^{\prime}\left(t_{0}\right)=0$ (keep also in mind that $\left\{x_{n_{j}, 1}^{\prime}\right\}$ converges to $x_{0,1}^{\prime}$ uniformly on $[0,1]$ and $x_{0,1}^{\prime}$ is continuous on $[0,1])$.

We now show that

$$
t_{0} \in(0,1) \text { and } x_{0,1}^{\prime}(t) \neq 0 \text { if } t \neq t_{0} .
$$

Suppose that $t_{0}=0$. Let $R^{\prime}=I^{-1}\left(I(\varepsilon)+h\left(R_{1}+\varepsilon\right) \int_{0}^{1} \Phi(s) d s\right)+1$. >From (3.4), there is a $\Psi_{R_{1}+\varepsilon, R^{\prime}} \in C[0,1]$ with $\Psi_{R_{1}+\varepsilon, R^{\prime}}(t)>0$ for all $t \in(0,1)$ such that $f\left(t, x_{n, 1}(t)+\right.$ $\left.\frac{1}{n} t,\left|x_{n, 1}^{\prime}(t)\right|+\frac{1}{n}\right) \geq \Psi_{R_{1}+\varepsilon, R^{\prime}}(t)\left(x_{n, 1}(t)+\frac{1}{n} t\right)^{\gamma} \geq \Psi_{R_{1}+\varepsilon, R^{\prime}}(t)\left(x_{n, 1}(t)\right)^{\gamma}, \quad t \in[0,1]$. Thus 
(note $x_{n, 1} \in P$ and Lemma 2.5),

$$
\begin{aligned}
x_{n, 1}(t) & \geq \int_{0}^{1} G(t, s) \Phi(s) \Psi_{R_{1}+\varepsilon, R^{\prime}}(s)\left(x_{n, 1}(s)\right)^{\gamma} d s \\
& \geq \int_{0}^{1} G(t, s) \Phi(s) \Psi_{R_{1}+\varepsilon, R^{\prime}}(s)(s(1-s))^{\gamma} d s\left\|x_{n, 1}\right\|_{1}^{\gamma} \\
& \geq t(1-t) \max _{t \in[0,1]} \int_{0}^{1} G(t, s) \Phi(s) \Psi_{R_{1}+\varepsilon, R^{\prime}}(s)(s(1-s))^{\gamma} d s\left\|x_{n, 1}\right\|_{1}^{\gamma}, \quad \forall t \in[0,1],
\end{aligned}
$$

which implies that

$$
\begin{aligned}
\left\|x_{n, 1}\right\|_{1} & \geq\left(\max _{t \in[0,1]} t(1-t)\right)\left(\max _{t \in[0,1]} \int_{0}^{1} G(t, s) \Phi(s) \Psi_{R_{1}+\varepsilon, R^{\prime}}(s)(s(1-s))^{\gamma} d s\left\|x_{n, 1}\right\|_{1}^{\gamma}\right) \\
& =\frac{1}{4} \max _{t \in[0,1]} \int_{0}^{1} G(t, s) \Phi(s) \Psi_{R_{1}+\varepsilon, R^{\prime}}(s)(s(1-s))^{\gamma} d s\left\|x_{n, 1}\right\|_{1}^{\gamma}
\end{aligned}
$$

and $\quad$ so $\quad\left\|x_{n, 1}\right\|_{1} \geq\left(\frac{1}{4} \max _{t \in[0,1]} \int_{0}^{1} G(t, s) \Phi(s) \Psi_{R_{1}+\varepsilon, R^{\prime}}(s)(s(1-s))^{\gamma} d s\right)^{\frac{1}{1-\gamma} \stackrel{\text { def. }}{=}} a_{0}>0$. Consequently,

$$
x_{n, 1}(t) \geq t(1-t)\left\|x_{n, 1}\right\|_{1} \geq t(1-t) a_{0}, \quad t \in[0,1] .
$$

Now (3.27) implies that for each $n \in N_{0}$,

$$
-x_{n, 1}^{\prime \prime}(t) \geq \Phi(t) \Psi_{R_{1}+\varepsilon, R^{\prime}}(t)(t(1-t))^{\gamma} a_{0}^{\gamma}, \quad t \in(0,1),
$$

and so $\quad x_{n_{j}, 1}^{\prime}\left(t_{n_{j}}\right)-x_{n_{j}, 1}^{\prime}(t) \geq \int_{t_{n_{j}}}^{t} \Phi(s) \Psi_{R_{1}+\varepsilon, R^{\prime}}(s)(s(1-s))^{\gamma} a_{0}^{\gamma} d s, \quad t>t_{n_{j}}$. Letting $j \rightarrow+\infty$, one has $x_{0,1}^{\prime}\left(t_{0}\right)-x_{n_{j}, 1}^{\prime}(t) \geq \int_{t_{0}}^{t} \Phi(s) \Psi_{R_{1}+\varepsilon, R^{\prime}}(s)(s(1-s))^{\gamma} a_{0}^{\gamma} d s, \quad t>t_{0}=0$, i.e., $x_{n_{j}, 1}^{\prime}(t) \leq-\int_{0}^{t} \Phi(s) \Psi_{R_{1}+\varepsilon, R^{\prime}}(s)(s(1-s))^{\gamma} a_{0}^{\gamma} d s<0, \quad t>0$, which means $x_{0,1}(t)$ is decreasing on $[0,1]$, a contradiction to $x_{0,1}(0)=x_{0,1}(1)$. Thus, $t_{0}>0$. Similarly, we get $t_{0}<1$. Hence, $t_{0} \in(0,1)$.

From (3.28), we have

$$
\begin{aligned}
& x_{n_{j}, 1}^{\prime}\left(t_{n_{j}}\right)-x_{n_{j}, 1}^{\prime}(t) \geq \int_{t_{n_{j}}}^{t} \Phi(s) \Psi_{R_{1}+\varepsilon, R^{\prime}}(s)(s(1-s))^{\gamma} a_{0}^{\gamma} d s, \quad t>t_{n_{j}}, \\
& x_{n_{j}, 1}^{\prime}(t)-x_{n_{j}, 1}^{\prime}\left(t_{n_{j}}\right) \geq \int_{t}^{t_{n_{j}}} \Phi(s) \Psi_{R_{1}+\varepsilon, R^{\prime}}(s)(s(1-s))^{\gamma} a_{0}^{\gamma} d s, \quad t<t_{n_{j}} .
\end{aligned}
$$

Letting $j \rightarrow+\infty$, one has

$$
\begin{gathered}
-x_{0,1}^{\prime}(t)=x_{0,1}^{\prime}\left(t_{0}\right)-x_{0,1}^{\prime}(t) \geq \int_{t_{0}}^{t} \Phi(s) \Psi_{R_{1}+\varepsilon, R^{\prime}}(s)(s(1-s))^{\gamma} a_{0}^{\gamma} d s, \quad t>t_{0}, \\
x_{0,1}^{\prime}(t)=x_{0,1}^{\prime}(t)-x_{0,1}^{\prime}\left(t_{0}\right) \geq \int_{t}^{t_{0}} \Phi(s) \Psi_{R_{1}+\varepsilon, R^{\prime}}(s)(s(1-s))^{\gamma} a_{0}^{\gamma} d s, \quad t<t_{0} .
\end{gathered}
$$

Consequently, one has $x_{0,1}^{\prime}(t) \neq 0$, if $t \neq t_{0}$. Therefore, (3.26) is true, which implies that, for any $\frac{\min \left\{t_{0}, 1-t_{0}\right\}}{2}>\varepsilon^{\prime}>0$, there exists an $N>0$ such that $t_{n_{j}} \in\left[t_{0}-\frac{\varepsilon^{\prime}}{2}, t_{0}+\frac{\varepsilon^{\prime}}{2}\right]$ 
(notice that $x_{n_{j}, 1}^{\prime}\left(t_{n_{j}}\right)=0$ ) for all $j \geq N$. Of course

$$
\min \left\{\inf _{j \geq N} \inf _{t \in\left[0, t_{0}-\varepsilon^{\prime}\right]}\left|x_{n_{j}}^{\prime}(t)\right| \inf _{j \geq N} \inf _{t \in\left[t_{0}+\varepsilon^{\prime}, 1\right]}\left|x_{n_{j}}^{\prime}(t)\right|\right\}=\delta_{0}>0,
$$

and so,

$$
\begin{aligned}
& \Phi(t)\left|f\left(t, x_{n_{j}, 1}(t)+\frac{1}{n_{j}} t,\left|x_{n_{j}, 1}^{\prime}(t)\right|+\frac{1}{n_{j}}\right)\right| \\
& \quad \leq h\left(R_{1}+\varepsilon\right)\left[g\left(\delta_{0}\right)+r\left(R^{\prime}\right)\right] \Phi(t), \quad t \in\left(0, t_{0}-\varepsilon^{\prime}\right] \cup\left[t_{0}+\varepsilon^{\prime}, 1\right) .
\end{aligned}
$$

The Lebesgue Dominated Convergence Theorem guarantees that

$$
\begin{aligned}
x_{0,1}^{\prime}(t)-x_{0,1}^{\prime}\left(t_{0}+\varepsilon^{\prime}\right) & =\lim _{j \rightarrow+\infty}\left[x_{n_{j}, 1}^{\prime}(t)-x_{n_{j}, 1}^{\prime}\left(t_{0}+\varepsilon^{\prime}\right)\right] \\
& =\lim _{j \rightarrow+\infty} \int_{t_{0}+\varepsilon^{\prime}}^{t} \Phi(s) f\left(s, x_{n_{j}, 1}(s)+\frac{1}{n_{j}} s,\left|x_{n_{j}, 1}^{\prime}(s)\right|+\frac{1}{n_{j}}\right) d s \\
& =\int_{t_{0}+\varepsilon^{\prime}}^{t} \Phi(s) f\left(s, x_{0,1}(s),\left|x_{0,1}^{\prime}(s)\right|\right) d s, \quad t \in\left[t_{0}+\varepsilon^{\prime}, 1\right)
\end{aligned}
$$

and similarly

$$
x_{0,1}^{\prime}(t)-x_{0,1}^{\prime}\left(t_{0}-\varepsilon^{\prime}\right)=\int_{t_{0}-\varepsilon^{\prime}}^{t} \Phi(s) f\left(s, x_{0,1}(s),\left|x_{0,1}^{\prime}(s)\right|\right) d s, \quad t \in\left(0, t_{0}-\varepsilon^{\prime}\right],
$$

which implies that $-x_{0,1}^{\prime \prime}(t)=\Phi(t) f\left(t, x_{0,1}(t),\left|x_{0,1}^{\prime}(t)\right|\right), \quad t \in\left(0, t_{0}-\varepsilon^{\prime}\right] \cup\left[t_{0}+\varepsilon^{\prime}, 1\right)$. Since $\varepsilon^{\prime}$ is arbitrary, we have $-x_{0,1}^{\prime \prime}(t)=\Phi(t) f\left(t, x_{0,1}(t),\left|x_{0,1}^{\prime}(t)\right|\right), \quad t \in\left(0, t_{0}\right) \cup\left(t_{0}, 1\right)$. In addition $x_{0,1}(0)=x_{0,1}(1)=0$, and $x_{0,1}$ is a solution of $(1.1)$ with $x_{0,1}(t)>0$ on $(0,1)$ and $\left\|x_{0,1}\right\|<R_{1}$.

For the set $\left\{x_{n, 2}\right\}_{n \in N_{0}} \subseteq\left(\Omega_{2}-\bar{\Omega}_{1}\right) \cap P$, a similar proof yields a convergent subsequence $\left\{x_{n_{i}, 2}\right\}$ of $\left\{x_{n, 2}\right\}$ with $\lim _{i \rightarrow+\infty} x_{n_{i}, 2}=x_{0,2} \in C^{1}[0,1]$. Also $x_{0,2}$ is a nonnegative solution of $(1.1)$ with $x_{0,2}(t)>0$ on $(0,1)$ and $R_{1}<\left\|x_{0,2}\right\|<\frac{4 R_{2}}{a^{*}\left(1-b^{*}\right)}$.

Consequently, (1.1) has at least two different nonnegative solutions $x_{0,1}$ and $x_{0,2}$ with $\left\|x_{0,1}\right\|<R_{1}<\left\|x_{0,2}\right\|$.

EXAMPLE 3.1. Consider the boundary value problems

$$
\left\{\begin{array}{l}
x^{\prime \prime}+\mu\left(y^{b}+y^{d}\right)\left(1+\left|x^{\prime}\right|^{-a}\right)=0 \\
x(0)=0, x(1)=0
\end{array}\right.
$$

with $0 \leq a, b>1,1>d \geq 0$ and $\mu>0$. If

$$
\mu<\frac{1}{1+a}\left(\sup _{c \in(0,+\infty)} \frac{c}{\left[c^{d}+c^{b}\right]^{\frac{1}{1+a}}}\right)^{1+a}
$$

then (3.29) has at least two nonnegative solutions.

To see that (3.29) has at least two nonnegative solutions, we will apply Theorem 3.1 with $\Phi(t) \equiv 1, f(t, x,|y|)=\mu\left(x^{b}+x^{d}\right)\left(1+|y|^{-a}\right), h(x)=\mu\left(x^{d}+x^{b}\right)$, $g(|y|)=1+|y|^{-a}, r(|y|)=0, g_{1}(x, y)=\mu\left(x^{b}\right)$ and $\Psi_{H, H^{\prime}}(t)=\mu$. It is easy to see that 
(3.1), (3.2), (3.4) and (3.5) hold. Since $I(z)=\int_{0}^{z} \frac{1}{1+u^{-a}} d u \leq \frac{1}{1+a} u^{1+a}=I_{1}(z)$, notice

$$
\sup _{c \in(0,+\infty)} \frac{c}{I^{-1}\left(h(c) \int_{0}^{1} \Phi(s) d s\right)} \geq \sup _{c \in(0,+\infty)} \frac{c}{I_{1}^{-1}\left(\mu\left(c^{d}+c^{b}\right)\right)},
$$

so (3.30) guarantees that (3.3) holds.

REMARK 3.1. Notice that (3.1)-(3.4) are only needed to guarantee the existence of $x_{0,1}$ in Theorem 3.1 .

4. Multiple positive solutions to (1.1) with singularity at $x=0$ and $x^{\prime}=0$. In this section our nonlinearity $f$ may be singular at $x=0$ and $x^{\prime}=0$. Throughout this section we will assume that the following conditions hold:

$$
\Phi \in C[0,1] \text { with } \Phi(t)>0 \text { on }(0,1)
$$

$\left\{\begin{array}{l}f:[0,1] \times(0,+\infty) \times(0,+\infty) \rightarrow(0,+\infty) \text { is continuous with } \\ f(t, x, y)>0 \text { for }(t, x, y) \in[0,1] \times(0,+\infty) \times(0,+\infty), \\ f(t, x, y) \leq[h(x)+w(x)][g(|y|)+r(|y|)] \text { on }[0,1] \times(0,+\infty) \times(0,+\infty) \text { with } \\ w>0, g>0 \text { continuous and nonincreasing on }(0,+\infty), \\ \int_{0}^{1} \Phi(s) r\left(k_{0} \frac{1}{s(1-s)}\right) d s<+\infty, \int_{0}^{k_{0}} w(s) d s<+\infty, \text { for all } k_{0}>0, \text { and } \\ h \geq 0, r \geq 0 \text { continuous and nondecreasing on }[0, \infty)\end{array}\right.$

$$
\left\{\begin{array}{l}
\sup _{c \in(0,+\infty)} \frac{c}{I^{-1}\left(c h(c)\|\Phi\|_{1}+\|\Phi\|_{1} \int_{0}^{c} w(s) d s\right)}>1 \\
\text { where } I(z)=\int_{0}^{z} \frac{u}{g(u)+r(u)} d u, z \in(0,+\infty)
\end{array}\right.
$$

$$
\left\{\begin{array}{l}
\text { for constants } H>0, H^{\prime}>0 \text { there exists a function } \psi_{H, H^{\prime}} \\
\text { continuous on }[0,1] \text { and positive on }(0,1) \text { such that } \\
f(t, x, y) \geq \psi_{H, H^{\prime}}(t) \text { on }[0,1] \times(0, H] \times\left(0, H^{\prime}\right]
\end{array}\right.
$$

and

$$
\left\{\begin{array}{l}
\text { there exists a } g_{1} \in C((0,+\infty) \times(0,+\infty),(0,+\infty)) \text { with } \\
f(t, x, y) \geq g_{1}(x, y), \forall(t, x, y) \in[0,1] \times(0,+\infty) \times(0,+\infty) \text { such that } \\
\lim _{x \rightarrow+\infty} \frac{g_{1}(x, y)}{x}=+\infty \text { uniformly for } y \in(0,+\infty)
\end{array}\right.
$$

THEOREM 4.1. Suppose that (4.1)-(4.5) hold. Then (1.1) has at least two nonnegative solutions $x_{0,1}, x_{0,2} \in C^{1}[0,1] \cap C^{2}(0,1)$ with $x_{0,1}(t)>0$ and $x_{0,2}(t)>0$ on $(0,1)$.

Proof. From (4.3) and the continuity of $I^{-1}$ and $h$, choose an $R_{1}>0$, and a $\varepsilon>0$ with $\varepsilon<\min \left\{\frac{R_{1}}{2}, 1\right\}$ and

$$
\frac{R_{1}}{I^{-1}\left(\left(R_{1}+\varepsilon\right) h\left(R_{1}+\varepsilon\right)\|\Phi\|_{1}+\|\Phi\|_{1} \int_{0}^{R_{1}+\varepsilon} w(s) d s\right)}>1 .
$$

Let $n_{0} \in\{1,2, \ldots\}$ be chosen so that $\frac{2}{n_{0}}<\varepsilon$, and let $N_{0}=\left\{n_{0}, n_{0}+1, \ldots\right\}$. For each $n \in N_{0}$, for $x \in P$, define

$$
\left(A_{n} x\right)(t)=\int_{0}^{1} G(t, s) \Phi(s) f\left(s, x(s)+\frac{1}{n} s+\frac{1}{n},\left|x^{\prime}(s)\right|+\frac{1}{n}\right) d s, \quad t \in[0,1] .
$$


Now (4.2) yields $f\left(t, x+\frac{1}{n} t+\frac{1}{n},\left|x^{\prime}\right|+\frac{1}{n}\right) \leq\left[h\left(x+\frac{2}{n}\right)+w\left(\frac{1}{n}\right)\right]\left[g\left(\frac{1}{n}\right)+r\left(\left|x^{\prime}\right|+\frac{1}{n}\right)\right]$, which implies that (2.10) is true. The Lemma 2.6 guarantees that $A_{n}: P \rightarrow P$ is continuous and completely continuous with $A_{n} P \subseteq C^{1}[0,1]$ for each $n \in N_{0}$.

Let

$$
\Omega_{1}=\left\{x \in C_{q}^{1}[0,1]:\|x\|<R_{1}\right\} .
$$

Choose $0<a^{*}<b^{*}<1$ and $N^{*}$ as in (3.8). From (4.5), there exists an $R_{2}>R_{1}$ such that

$$
g_{1}(x, y) \geq N^{*} x, \quad \forall x \geq R_{2}, y \in(0,+\infty)
$$

Let

$$
\Omega_{2}=\left\{x \in C_{q}^{1}[0,1]:\|x\|<\frac{4 R_{2}}{a^{*}\left(1-b^{*}\right)}\right\} .
$$

Then, for each $n \in N_{0}$, we claim that

$$
\mu A_{n} x \neq x, \quad \forall \mu \in(0,1], \quad x \in P \cap \partial \Omega_{1},
$$

and

$$
A_{n} x \not \leq x, \quad \forall x \in P \cap \partial \Omega_{2} .
$$

First we show that (4.9) is true. Suppose that there exists an $x_{0} \in P \cap \partial \Omega_{1}$ and a $\mu_{0} \in(0,1]$ such that $x_{0}=\mu_{0} A_{n} x_{0}$. Then

$x_{0}^{\prime \prime}(t)+\mu_{0} \Phi(t) f\left(t, x_{0}(t)+\frac{1}{n} t+\frac{1}{n},\left|x_{0}^{\prime}(t)\right|+\frac{1}{n}\right)=0, t \in(0,1), x_{0}(0)=0, x_{0}(1)=0$,

which means that $x_{0}(t)>0$ on $(0,1)$ with $x_{0}(0)=x_{0}(1)=0$ and $x_{0}^{\prime}(t)$ is decreasing on $(0,1)$. Thus, there exists a unique $t_{0} \in(0,1)$ with $x_{0}^{\prime}\left(t_{0}\right)=0, x_{0}^{\prime}(t)>0$ on $\left(0, t_{0}\right)$ and $x_{0}^{\prime}(t)<0$ on $\left(t_{0}, 1\right)$ and $\left\|x_{0}\right\|_{1}=x_{0}\left(t_{0}\right)$. As a result (follow the argument used to prove (3.12), (3.13), (3.14), (3.15) and (3.16))

$$
\begin{gathered}
\frac{-\left(x_{0}^{\prime}(t)+\frac{1}{n}\right) x_{0}^{\prime \prime}(t)}{g\left(x_{0}^{\prime}(t)+\frac{1}{n}\right)+r\left(x_{0}^{\prime}(t)+\frac{1}{n}\right)} \\
\leq\left[h\left(x_{0}(t)+\frac{1}{n} t+\frac{1}{n}\right)+w\left(x_{0}(t)+\frac{1}{n} t+\frac{1}{n}\right)\right]\left(x_{0}^{\prime}(t)+\frac{1}{n}\right)\|\Phi\|_{1}, \quad \forall t \in\left(0, t_{0}\right), \\
\quad x_{0}^{\prime}(t) \leq I^{-1}\left(I(\varepsilon)+\|\Phi\|_{1} h\left(R_{1}+\varepsilon\right)\left(R_{1}+\varepsilon\right)+\|\Phi\|_{1} \int_{0}^{R_{1}+\varepsilon} w(s) d s\right), \\
\left\|x_{0}\right\|_{1}=x_{0}\left(t_{0}\right)-x_{0}(0) \leq I^{-1}\left(I(\varepsilon)+\|\Phi\|_{1} h\left(R_{1}+\varepsilon\right)\left(R_{1}+\varepsilon\right)+\|\Phi\|_{1} \int_{0}^{R_{1}+\varepsilon} w(s) d s\right), \\
\quad-\left(-x_{0}^{\prime}(t)+\frac{1}{n}\right) x_{0}^{\prime \prime}(t) \\
\frac{g\left(-x_{0}^{\prime}(t)+\frac{1}{n}\right)+r\left(-x_{0}^{\prime}(t)+\frac{1}{n}\right)}{\leq} \\
{\left[h\left(R_{1}+\varepsilon\right)+w\left(x_{0}(t)-\frac{1}{n} t+\frac{1}{n}\right)\right]\left(-x_{0}(t)+\frac{1}{n} t-\frac{1}{n}\right)^{\prime}\|\Phi\|_{1}, \quad \forall t \in\left[t_{0}, 1\right),}
\end{gathered}
$$




$$
-x_{0}^{\prime}(t)<I^{-1}\left(I(\varepsilon)+\|\Phi\|_{1} h\left(R_{1}+\varepsilon\right)\left(R_{1}+\varepsilon\right)+\|\Phi\|_{1} \int_{0}^{R_{1}+\varepsilon} w(s) d s\right), \forall t \in\left[t_{0}, 1\right)
$$

and

$$
\begin{aligned}
\sup _{t \in(0,1)} t(1-t)\left|x_{0}^{\prime}(t)\right| \leq & I^{-1}\left(I(\varepsilon)+\|\Phi\|_{1} h\left(R_{1}+\varepsilon\right)\left(R_{1}+\varepsilon\right)\right. \\
& \left.+\|\Phi\|_{1} \int_{0}^{R_{1}+\varepsilon} w(s) d s\right), \forall t \in(0,1) .
\end{aligned}
$$

Now (4.16) and (4.13) guarantee that

$$
R_{1}=\max \left\{\left\|x_{0}\right\|_{1},\left\|x_{0}\right\|_{2}\right\} \leq I^{-1}\left(I(\varepsilon)+\|\Phi\|_{1} h\left(R_{1}+\varepsilon\right)\left(R_{1}+\varepsilon\right)+\|\Phi\|_{1} \int_{0}^{R_{1}+\varepsilon} w(s) d s\right),
$$

which means that

$$
\frac{R_{1}}{I^{-1}\left(I(\varepsilon)+\|\Phi\|_{1} h\left(R_{1}+\varepsilon\right)\left(R_{1}+\varepsilon\right)+\|\Phi\|_{1} \int_{0}^{R_{1}+\varepsilon} w(s) d s\right)} \leq 1,
$$

a contradiction to (4.6). Then, (4.9) is true.

Next we show that (4.10) is true. Suppose that there is an $x_{0} \in P \cap \partial \Omega_{2}$ with $x_{0} \geq A_{n} x_{0}$. Then by the definition of the cone and Lemma 2.4 , one has $x_{0}(t) \geq t(1-$ $t)\left\|x_{0}\right\|_{1} \geq a^{*}\left(1-b^{*}\right) \frac{1}{4}\left\|x_{0}\right\|=a^{*}\left(1-b^{*}\right) \frac{1}{4} \frac{4 R_{2}}{a^{*}\left(1-b^{*}\right)}=R_{2}, \quad \forall t \in\left[a^{*}, b^{*}\right]$. Clearly for $t \in$ $\left[a^{*}, b^{*}\right], x_{0}(t)+\frac{1}{n} t+\frac{1}{n} \geq R_{2}, \quad \forall t \in\left[a^{*}, b^{*}\right]$. Then, for $t \in\left[a^{*}, b^{*}\right]$, from (4.8), one has

$$
\begin{aligned}
x_{0}(t) & \geq\left(A_{n} x_{0}\right)(t) \geq \int_{a^{*}}^{b^{*}} G(t, s) \Phi(s) g_{1}\left(x_{0}(s)+\frac{1}{n} s+\frac{1}{n},\left|x_{0}^{\prime}(s)\right|+\frac{1}{n}\right) d s \\
& \geq \int_{a^{*}}^{b^{*}} G(t, s) \Phi(s) N^{*}\left(x_{0}(s)+\frac{1}{n} s+\frac{1}{n}\right) d s \geq \int_{a^{*}}^{b^{*}} G(t, s) \Phi(s) d s N^{*} R_{2} \\
& =a^{*}\left(1-b^{*}\right) \frac{1}{4} \min _{t \in\left[a^{*}, b^{*}\right]} \int_{a^{*}}^{b^{*}} G(t, s) \Phi(s) d s N^{*} \frac{4 R_{2}}{a^{*}\left(1-b^{*}\right)}>\frac{4 R_{2}}{a^{*}\left(1-b^{*}\right)},
\end{aligned}
$$

which implies that $\left\|x_{0}\right\| \geq\left\|x_{0}\right\|_{1}>\frac{4 R_{2}}{a^{*}\left(1-b^{*}\right)}$, a contradiction to $x_{0} \in P \cap \partial \Omega_{2}$. Then, (4.10) is true.

Lemma 2.2 and Lemma 2.3 guarantee that

$$
i\left(A_{n}, P \cap \Omega_{1}, P\right)=1, \quad i\left(A_{n}, P \cap \Omega_{2}, P\right)=0 .
$$

Thus

$$
i\left(A_{n}, P \cap\left(\Omega_{2}-\bar{\Omega}_{1}\right), P\right)=-1, \quad n \in N_{0} .
$$

As a result, for each $n \in N_{0}$, there exist $x_{n, 1} \in P \cap \Omega_{1}$ and $x_{n, 2} \in P \cap\left(\Omega_{2}-\bar{\Omega}_{1}\right)$ such that $x_{n, 1}=A_{n} x_{n, 1}$ and $x_{n, 2}=A_{n} x_{n, 2}$.

Now we consider $\left\{x_{n, 1}\right\}_{n \in N_{0}}$ and $\left\{x_{n, 2}\right\}_{n \in N_{0}}$. It is easy to see that the functions belonging to $\left\{x_{n, 1}(t)\right\}$ are uniformly bounded on $[0,1]$ with $\max _{t \in[0,1]}\left|x_{n, 1}(t)\right| \leq R_{1}$, $n \in N_{0}$. 
For each $n \in N_{0}$ one has

$x_{n, 1}^{\prime \prime}(t)+\Phi(t) f\left(t, x_{n, 1}(t)+\frac{1}{n} t+\frac{1}{n},\left|x_{n, 1}^{\prime}(t)\right|+\frac{1}{n}\right)=0, t \in(0,1), x_{n, 1}(0)=0, x_{n, 1}(1)=0$,

which means that $x_{n, 1}(t)>0$ on $(0,1)$ with $x_{n, 1}(0)=x_{n, 1}(1)=0$ and $x_{n, 1}^{\prime}(t)$ is decreasing on $(0,1)$ and there exists a unique $t_{n} \in(0,1)$ with $x_{n, 1}^{\prime}\left(t_{n}\right)=0, x_{n, 1}^{\prime}\left(t_{n}\right)>0$ on $\left(0, t_{n}\right)$ and $x_{n, 1}^{\prime}(t)<0$ on $\left(t_{n}, 1\right)$ and $\left\|x_{n, 1}\right\|_{1}=x_{n, 1}\left(t_{n, 1}\right)$. Following the ideas used to prove (4.11) and (4.14) yields

$$
\begin{aligned}
& \frac{-\left(\left|x_{n, 1}^{\prime}(t)\right|+\frac{1}{n}\right) x_{n, 1}^{\prime \prime}(t)}{g\left(\left|x_{n, 1}^{\prime}(t)\right|+\frac{1}{n}\right)+r\left(\left|x_{n, 1}^{\prime}(t)\right|+\frac{1}{n}\right)} \\
& \quad \leq\left[h\left(x_{n, 1}(t)+\frac{1}{n} t+\frac{1}{n}\right)+w\left(x_{n, 1}(t)+\frac{1}{n} t+\frac{1}{n}\right)\right] \underset{ }{\left(\left|x_{n, 1}^{\prime}(t)\right|+\frac{1}{n}\right)\|\Phi\|_{1},} \\
& \quad t \in\left(0, t_{n}\right) \cup\left(t_{n}, 1\right) .
\end{aligned}
$$

A similar argument to that used to prove (4.12) and (4.15) yields

$$
\sup _{n \geq n_{0}} \sup _{t \in(0,1)}\left|x_{n, 1}^{\prime}(t)\right| \leq I^{-1}\left(I(\varepsilon)+\|\Phi\|_{1} h\left(R_{1}+\varepsilon\right)\left(R_{1}+\varepsilon\right)+\|\Phi\|_{1} \int_{0}^{R_{1}+\varepsilon} w(s) d s\right),
$$

i.e., the functions belonging to $\left\{x_{n, 1}^{\prime}(t)\right\}$ are uniformly bounded on $[0,1]$, which guarantees that the functions belonging to $\left\{x_{n, 1}(t)\right\}$ are equicontinuous on $[0,1]$.

Next we show that the functions belonging to $\left\{x_{n, 1}^{\prime}(t)\right\}$ are equicontinuous on $[0,1]$. For any $t_{1}, t_{2} \in[0,1],(4.20)$ yields

$$
\begin{aligned}
& \left|I\left(\left|x_{n, 1}^{\prime}\left(t_{2}\right)\right|+\frac{1}{n}\right)-I\left(\left|x_{n, 1}^{\prime}\left(t_{1}\right)\right|+\frac{1}{n}\right)\right| \\
& \quad \leq\|\Phi\|_{1}\left[h\left(R_{1}+\varepsilon\right)\left(\left|x_{n, 1}\left(t_{1}\right)-x_{n, 1}\left(t_{2}\right)\right|+\left|t_{1}-t_{2}\right|\right)+\left|\int_{x_{n, 1}\left(t_{1}\right)-\frac{1}{n} t_{1}+\frac{1}{n}}^{x_{n, 1}\left(t_{2}\right)-\frac{1}{n} t_{2}+\frac{1}{n}} w(s) d s\right|\right],
\end{aligned}
$$

if $t_{2}>t_{1}>t_{n}$ and

$$
\begin{aligned}
& \left|I\left(\left|x_{n, 1}^{\prime}\left(t_{2}\right)\right|+\frac{1}{n}\right)-I\left(\left|x_{n, 1}^{\prime}\left(t_{1}\right)\right|+\frac{1}{n}\right)\right| \\
& \quad \leq\|\Phi\|_{1} \mid\left[h\left(R_{1}+\varepsilon\right)\left(\left|x_{n, 1}\left(t_{1}\right)-x_{n, 1}\left(t_{2}\right)\right|+\left|t_{1}-t_{2}\right|\right)+\left|\int_{x_{n, 1}\left(t_{1}\right)+\frac{1}{n} t_{1}+\frac{1}{n}}^{x_{n, 1}\left(t_{2}\right)+\frac{1}{n} t_{2}+\frac{1}{n}} w(s) d s\right|\right],
\end{aligned}
$$

if $t_{2}<t_{1}<t_{n}$, which guarantee that

$$
\begin{aligned}
& \left|I\left(\left|x_{n, 1}^{\prime}\left(t_{2}\right)\right|+\frac{1}{n}\right)-I\left(\left|x_{n, 1}^{\prime}\left(t_{1}\right)\right|+\frac{1}{n}\right)\right| \\
& \leq\left|I\left(\left|x_{n, 1}^{\prime}\left(t_{2}\right)\right|+\frac{1}{n}\right)-I\left(\left|x_{n, 1}^{\prime}\left(t_{n}\right)\right|+\frac{1}{n}\right)\right|+\left|I\left(\left|x_{n, 1}^{\prime}\left(t_{1}\right)\right|+\frac{1}{n}\right)-I\left(\left|x_{n, 1}^{\prime}\left(t_{n}\right)\right|+\frac{1}{n}\right)\right| \\
& \quad \leq\|\Phi\|_{1} \mid\left[h\left(R_{1}+\varepsilon\right)\left(\left|x_{n, 1}^{\prime}\left(t_{2}\right)-x_{n, 1}^{\prime}\left(t_{n}\right)\right|+\left|t_{2}-t_{n}\right|\right)+\left|\int_{x_{n, 1}\left(t_{n}\right)-\frac{1}{n} t_{n}+\frac{1}{n}}^{x_{n, 1}\left(t_{2}\right)-\frac{1}{n} t_{2}+\frac{1}{n}} w(s) d s\right|\right] \\
& \quad+\|\Phi\|_{1} \mid\left[h\left(R_{1}+\varepsilon\right)\left(\left|x_{n, 1}^{\prime}\left(t_{1}\right)-x_{n, 1}^{\prime}\left(t_{n}\right)\right|+\left|t_{1}-t_{n}\right|\right)+\left|\int_{x_{n, 1}\left(t_{n}\right)+\frac{1}{n} t_{n}+\frac{1}{n}}^{x_{n, 1}\left(t_{1}\right)+\frac{1}{n} t_{1}+\frac{1}{n}} w(s) d s\right|\right],
\end{aligned}
$$


if $t_{2}>t_{n}>t_{1}$ or

$$
\begin{aligned}
& \left|I\left(\left|x_{n, 1}^{\prime}\left(t_{2}\right)\right|+\frac{1}{n}\right)-I\left(\left|x_{n, 1}^{\prime}\left(t_{1}\right)\right|+\frac{1}{n}\right)\right| \\
& \quad \leq\|\Phi\|_{1} \mid\left[h\left(R_{1}+\varepsilon\right)\left(\left|x_{n, 1}^{\prime}\left(t_{2}\right)-x_{n, 1}^{\prime}\left(t_{n}\right)\right|+\left|t_{2}-t_{n}\right|\right)+\left|\int_{x_{n, 1}\left(t_{n}\right)+\frac{1}{n} t_{n}+\frac{1}{n}}^{x_{n, 1}\left(t_{2}\right)+\frac{1}{n} t_{2}+\frac{1}{n}} w(s) d s\right|\right] \\
& \quad+\|\Phi\|_{1} \mid\left[h\left(R_{1}+\varepsilon\right)\left(\left|x_{n, 1}^{\prime}\left(t_{1}\right)-x_{n, 1}^{\prime}\left(t_{n}\right)\right|+\left|t_{1}-t_{n}\right|\right)+\left|\int_{x_{n, 1}\left(t_{n}\right)-\frac{1}{n} t_{n}+\frac{1}{n}}^{x_{n, 1}\left(t_{1}\right)-\frac{1}{n} t_{1}+\frac{1}{n}} w(s) d s\right|\right],
\end{aligned}
$$

if $t_{2}<t_{n}<t_{1}$.

The uniform continuity of $\int_{0}^{z} w(s) d s$ on bounded interval implies that for any $\varepsilon^{\prime}>0$, there is a $\delta>0$ such that $\left|\int_{z_{1}}^{z_{2}} w(s) d s\right|<\frac{\varepsilon^{\prime}}{4\|\Phi\|_{1}},\left|z_{1}-z_{2}\right|<\delta, z_{1}, z_{2} \in\left[0, R_{1}+\varepsilon\right]$. Also the equicontinuity of $\left\{x_{n, 1}(t)\right\}$ implies that there is a $\min \left\{\frac{\delta}{2}, \frac{\varepsilon^{\prime}}{8\|\Phi\|_{1} h\left(R_{1}+\varepsilon\right)}\right\}>\delta^{\prime}>0$ such that $\left|x_{n, 1}\left(t_{1}\right)-x_{n, 1}\left(t_{2}\right)\right|<\min \left\{\frac{\delta}{2}, \frac{\varepsilon^{\prime}}{8\|\Phi\|_{1} h\left(R_{1}+\varepsilon\right)}\right\}, \quad \forall n \in N_{0}, \quad\left|t_{1}-t_{2}\right|<\delta^{\prime}, t_{1}, t_{2} \in$ $[0,1]$. Consequently,

$$
\begin{aligned}
& \left|I\left(\left|x_{n, 1}^{\prime}\left(t_{2}\right)\right|+\frac{1}{n}\right)-I\left(\left|x_{n, 1}^{\prime}\left(t_{1}\right)\right|+\frac{1}{n}\right)\right| \\
& \quad \leq\|\Phi\|_{1}\left[h\left(R_{1}+\varepsilon\right)\left(\frac{\varepsilon^{\prime}}{8\|\Phi\|_{1} h\left(R_{1}+\varepsilon\right)}+\frac{\varepsilon^{\prime}}{8\|\Phi\|_{1} h\left(R_{1}+\varepsilon\right)}\right)+\frac{\varepsilon^{\prime}}{4\|\Phi\|_{1}}\right]<\frac{\varepsilon^{\prime}}{2},
\end{aligned}
$$

if $t_{2}>t_{1}>t_{n}$ and

$$
\begin{aligned}
& \left|I\left(\left|x_{n, 1}^{\prime}\left(t_{2}\right)\right|+\frac{1}{n}\right)-I\left(\left|x_{n, 1}^{\prime}\left(t_{1}\right)\right|+\frac{1}{n}\right)\right| \\
& \quad \leq\|\Phi\|_{1}\left[h\left(R_{1}+\varepsilon\right)\left(\frac{\varepsilon^{\prime}}{8\|\Phi\|_{1} h\left(R_{1}+\varepsilon\right)}+\frac{\varepsilon^{\prime}}{8\|\Phi\|_{1} h\left(R_{1}+\varepsilon\right)}\right)+\frac{\varepsilon^{\prime}}{4\|\Phi\|_{1}}\right]<\frac{\varepsilon^{\prime}}{2},
\end{aligned}
$$

if $t_{2}<t_{1}<t_{n}$, which guarantee that

$$
\begin{aligned}
& \left|I\left(\left|x_{n, 1}^{\prime}\left(t_{2}\right)\right|+\frac{1}{n}\right)-I\left(\left|x_{n, 1}^{\prime}\left(t_{1}\right)\right|+\frac{1}{n}\right)\right| \\
& \quad \leq\|\Phi\|_{1} \mid\left[h\left(R_{1}+\varepsilon\right)\left(\frac{\varepsilon^{\prime}}{8\|\Phi\|_{1} h\left(R_{1}+\varepsilon\right)}+\frac{\varepsilon^{\prime}}{8\|\Phi\|_{1} h\left(R_{1}+\varepsilon\right)}\right)+\frac{\varepsilon^{\prime}}{4\|\Phi\|_{1}}\right] \\
& \quad+\|\Phi\|_{1} \mid\left[h\left(R_{1}+\varepsilon\right)\left(\frac{\varepsilon^{\prime}}{8\|\Phi\|_{1} h\left(R_{1}+\varepsilon\right)}+\frac{\varepsilon^{\prime}}{8\|\Phi\|_{1} h\left(R_{1}+\varepsilon\right)}\right)+\frac{\varepsilon^{\prime}}{4\|\Phi\|_{1}}\right]<\varepsilon^{\prime},
\end{aligned}
$$

if $t_{2}>t_{n}>t_{1}$ or

$$
\begin{aligned}
& \left|I\left(\left|x_{n, 1}^{\prime}\left(t_{2}\right)\right|+\frac{1}{n}\right)-I\left(\left|x_{n, 1}^{\prime}\left(t_{1}\right)\right|+\frac{1}{n}\right)\right| \\
& \quad \leq\|\Phi\|_{1} \mid\left[h\left(R_{1}+\varepsilon\right)\left(\frac{\varepsilon^{\prime}}{8\|\Phi\|_{1} h\left(R_{1}+\varepsilon\right)}+\frac{\varepsilon^{\prime}}{8\|\Phi\|_{1} h\left(R_{1}+\varepsilon\right)}\right)+\frac{\varepsilon^{\prime}}{4\|\Phi\|_{1}}\right] \\
& \quad+\|\Phi\|_{1} \mid\left[h\left(R_{1}+\varepsilon\right)\left(\frac{\varepsilon^{\prime}}{8\|\Phi\|_{1} h\left(R_{1}+\varepsilon\right)}+\frac{\varepsilon^{\prime}}{8\|\Phi\|_{1} h\left(R_{1}+\varepsilon\right)}\right)+\frac{\varepsilon^{\prime}}{4\|\Phi\|_{1}}\right]<\varepsilon^{\prime},
\end{aligned}
$$


if $t_{2}<t_{n}<t_{1}$, which means that the functions belonging to $\left\{I\left(\left|x_{n, 1}^{\prime}(t)\right|+\frac{1}{n}\right)\right\}$ are equicontinuous on $[0,1]$. By the continuity of $I^{-1}(z)$, we know that the functions belonging to $\left\{\left|x_{n, 1}^{\prime}(t)\right|+\frac{1}{n}\right\}$ are equicontinuous on $[0,1]$, which implies the functions belonging to $\left\{\left|x_{n, 1}^{\prime}(t)\right|\right\}$ are equicontinuous on [0,1]. Then, for any $\varepsilon^{\prime}>0$, there is a $\delta>0$ such that $\left\|x_{n, 1}^{\prime}\left(t_{1}\right)|-| x_{n, 1}^{\prime}\left(t_{2}\right)\right\|<\varepsilon^{\prime}, \forall\left|t_{1}-t_{2}\right|<\delta, t_{1}, t_{2} \in[0,1]$, which implies $\left|x_{n, 1}^{\prime}\left(t_{1}\right)-x_{n, 1}^{\prime}\left(t_{2}\right)\right|=\left\|x_{n, 1}^{\prime}\left(t_{1}\right)|-| x_{n, 1}^{\prime}\left(t_{2}\right)\right\|<\varepsilon^{\prime}, \forall\left|t_{1}-t_{2}\right|<\delta, t_{1}, t_{2} \leq t_{n} \in[0,1], \mid x_{n, 1}^{\prime}\left(t_{1}\right)-$ $x_{n, 1}^{\prime}\left(t_{2}\right)\left|=\left\|x_{n, 1}^{\prime}\left(t_{1}\right)|-| x_{n, 1}^{\prime}\left(t_{2}\right)\right\|<\varepsilon^{\prime}, \forall\right| t_{1}-t_{2} \mid<\delta, t_{1}, t_{2} \geq t_{n} \in[0,1]$ and

$$
\begin{aligned}
\left|x_{n, 1}^{\prime}\left(t_{1}\right)-x_{n, 1}^{\prime}\left(t_{2}\right)\right| & \leq\left|x_{n, 1}^{\prime}\left(t_{1}\right)-x_{n, 1}^{\prime}\left(t_{n}\right)\right|+\left|x_{n, 1}^{\prime}\left(t_{n}\right)-x_{n, 1}^{\prime}\left(t_{2}\right)\right| \\
& =\left\|x_{n, 1}^{\prime}\left(t_{1}\right)|-| x_{n, 1}^{\prime}\left(t_{n}\right)\right\|+\left\|x_{n, 1}^{\prime}\left(t_{n}\right)|-| x_{n, 1}^{\prime}\left(t_{2}\right)\right\| \\
& <2 \varepsilon^{\prime}, \quad \forall\left|t_{1}-t_{2}\right|<\delta, t_{1}<t_{n}<t_{2} \in[0,1], \text { or } t_{2}<t_{n}<t_{1} \in[0,1],
\end{aligned}
$$

which means that the functions belonging to $\left\{x_{n, 1}^{\prime}(t)\right\}$ are equicontinuous on $[0,1]$.

The Arzela-Ascoli Theorem guarantees that $\left\{x_{n, 1}\right\}$ is relatively compact in $C^{1}[0,1]$, i.e., that there is a convergence subsequence $\left\{x_{n_{j}, 1}\right\}$ of $\left\{x_{n, 1}\right\}$ such that $\lim _{j \rightarrow+\infty} x_{n_{j}, 1}=$ $x_{0,1} \in C^{1}[0,1]$ with $x_{n_{j}, 1}^{\prime}\left(t_{n_{j}}\right)=0$. Without loss of generality, we assume that $t_{n_{j}} \rightarrow t_{0} \in$ $[0,1]$ as $j \rightarrow+\infty$. Clearly $x_{0,1}^{\prime}\left(t_{0}\right)=0$ (keep also in mind that $\left\{x_{n_{j}, 1}^{\prime}\right\}$ converges to $x_{0,1}^{\prime}$ uniformly on $[0,1]$ and $x_{0,1}^{\prime}$ is continuous on $\left.[0,1]\right)$.

Now we show that

$$
t_{0} \in(0,1), \quad \text { and } \quad x_{0,1}^{\prime}(t) \neq 0 \text { for all } t \in(0,1) \backslash\left\{t_{0}\right\} .
$$

Suppose $t_{0}=0$. Let $R^{\prime}=I^{-1}\left(I(\varepsilon)+\|\Phi\|_{1} h\left(R_{1}+\varepsilon\right)\left(R_{1}+\varepsilon\right)+\|\Phi\|_{1} \int_{0}^{R_{1}+\varepsilon} w(s) d s\right)+1$. From (4.4), there is a $\Psi_{R_{1}+\varepsilon, R^{\prime}} \in C[0,1]$ with $\Psi_{R_{1}+\varepsilon, R^{\prime}}(t)>0$ for all $t \in(0,1)$ such that

$$
\begin{aligned}
-x_{n_{j}, 1}^{\prime \prime}(t) & =\Phi(t) f\left(t, x_{n_{j}, 1}(t)+\frac{1}{n_{j}} t+\frac{1}{n_{j}},\left|x_{n_{j}, 1}^{\prime}(t)\right|+\frac{1}{n_{j}}\right) \\
& \geq \Phi(t) \Psi_{R_{1}+\varepsilon, R^{\prime}}(t), \quad t \in(0,1) .
\end{aligned}
$$

Then $x_{n_{j}, 1}^{\prime}\left(t_{n_{j}}\right)-x_{n_{j}, 1}^{\prime}(t) \geq \int_{t_{n_{j}}}^{t} \Phi(s) \Psi_{R_{1}+\varepsilon, R^{\prime}}(s) d s, t \in\left(t_{n_{j}}, 1\right)$. Letting $j \rightarrow+\infty$, we have

$$
-x_{0,1}^{\prime}(t) \geq \int_{t_{0}}^{t} \Phi(s) \Phi_{R_{1}+\varepsilon, R^{\prime}}(s) d s=\int_{0}^{t} \Phi(s) \Phi_{R_{1}+\varepsilon, R^{\prime}}(s) d s, \quad t \in(0,1),
$$

which means $x_{0,1}(t)$ is decreasing on $(0,1)$, a contradiction to $x_{0,1}(0)=x_{0,1}(1)$. Similarly, we get $t_{0}<1$.

Moreover, (4.22) implies that

$$
\begin{aligned}
& x_{n_{j}, 1}^{\prime}\left(t_{n_{j}}\right)-x_{n_{j}, 1}^{\prime}(t) \geq \int_{t_{n_{j}}}^{t} \Phi(s) \Psi_{R_{1}+\varepsilon, R^{\prime}}(s) d s, t \in\left(t_{n_{j}}, 1\right), \\
& x_{n_{j}, 1}^{\prime}(t)-x_{n_{j}, 1}^{\prime}\left(t_{n_{j}}\right) \geq \int_{t}^{t_{n_{j}}} \Phi(s) \Psi_{R_{1}+\varepsilon, R^{\prime}}(s) d s, t \in\left(0, t_{n_{j}}\right) .
\end{aligned}
$$

Letting $j \rightarrow+\infty$, one gets

$$
\begin{aligned}
-x_{0,1}^{\prime}(t) & \geq \int_{t_{0}}^{t} \Phi(s) \Psi_{R_{1}+\varepsilon, R^{\prime}}(s) d s, t \in\left(t_{0}, 1\right), \quad \text { and } x_{0,1}^{\prime}(t) \\
& \geq \int_{t}^{t_{0}} \Phi(s) \Psi_{R_{1}+\varepsilon, R^{\prime}}(s) d s, \quad t \in\left(0, t_{0}\right),
\end{aligned}
$$

which implies that $x_{0,1}^{\prime}(t) \neq 0$ for all $t \neq t_{0}$. Hence, (4.21) is true. 
Consequently, for any $\frac{\min \left\{t_{0}, 1-t_{0}\right\}}{2}>\varepsilon^{\prime}>0$, there exists an $N>0$ such that $t_{n_{j}} \in$ $\left[t_{0}-\frac{\varepsilon^{\prime}}{2}, t_{0}+\frac{\varepsilon^{\prime}}{2}\right]$ for all $j \geq N$, which guarantees that

$$
\min \left\{\inf _{j \geq N} \inf _{t \in\left(0, t_{0}-\varepsilon^{\prime}\right]}\left|x_{n_{j}}^{\prime}(t)\right|, \inf _{j \geq N} \inf _{t \in\left[t_{0}+\varepsilon^{\prime}, 1\right)}\left|x_{n_{j}}^{\prime}(t)\right|\right\}=\delta_{0}>0 .
$$

On the other hand, Lemma 2.5 yields

$$
\begin{aligned}
x_{n_{j}, 1}(t) & \geq \int_{0}^{1} G(t, s) \Phi(s) \Psi_{R_{1}+\varepsilon, R^{\prime}}(s) d s \\
& \geq t(1-t) \max _{t \in[0,1]} \int_{0}^{1} G(t, s) \Phi(s) \Psi_{R_{1}+\varepsilon, R^{\prime}}(s) d s \\
& \geq \varepsilon^{\prime 2} \max _{t \in[0,1]} \int_{0}^{1} G(t, s) \Phi(s) \Psi_{R_{1}+\varepsilon, R^{\prime}}(s) d s, \quad t \in\left[\varepsilon^{\prime}, 1-\varepsilon^{\prime}\right] .
\end{aligned}
$$

Let $\delta_{0}^{\prime}=\varepsilon^{\prime 2} \max _{t \in[0,1]} \int_{0}^{1} G(t, s) \Phi(s) \Psi_{R_{1}+\varepsilon, R^{\prime}}(s) d s$. Then,

$$
\begin{aligned}
& \Phi(t)\left|f\left(t, x_{n_{j}, 1}(t)+\frac{1}{n_{j}} t+\frac{1}{n_{j}},\left|x_{n_{j}, 1}^{\prime}(t)\right|+\frac{1}{n_{j}}\right)\right| \\
& \quad \leq\left[h\left(R_{1}+1\right)+w\left(\delta_{0}^{\prime}\right)\right]\left[g\left(\delta_{0}\right)+r\left(R^{\prime}\right)\right] \Phi(t), \quad t \in\left[\varepsilon^{\prime}, t_{0}-\varepsilon^{\prime}\right] \cup\left[t_{0}+\varepsilon^{\prime}, 1-\varepsilon^{\prime}\right] .
\end{aligned}
$$

Hence, the Lebesgue Dominated Convergence Theorem guarantees that

$$
\begin{aligned}
x_{0,1}^{\prime}(t)-x_{0,1}^{\prime}\left(t_{0}+\varepsilon^{\prime}\right) & =\lim _{j \rightarrow+\infty}\left[x_{n_{j}, 1}^{\prime}(t)-x_{n_{j}, 1}^{\prime}\left(t_{0}+\varepsilon^{\prime}\right)\right] \\
& =\lim _{j \rightarrow+\infty} \int_{t_{0}+\varepsilon^{\prime}}^{t} \Phi(s) f\left(s, x_{n_{j}, 1}(s)+\frac{1}{n_{j}} s+\frac{1}{n_{j}},\left|x_{n_{j}, 1}^{\prime}(s)\right|+\frac{1}{n_{j}}\right) d s \\
& =\int_{t_{0}+\varepsilon^{\prime}}^{t} \Phi(s) f\left(s, x_{0,1}(s),\left|x_{0,1}^{\prime}(s)\right|\right) d s, \quad t \in\left[t_{0}+\varepsilon^{\prime}, 1-\varepsilon^{\prime}\right]
\end{aligned}
$$

and similarly

$$
x_{0,1}^{\prime}(t)-x_{0,1}^{\prime}\left(t_{0}-\varepsilon^{\prime}\right)=\int_{t_{0}-\varepsilon^{\prime}}^{t} \Phi(s) f\left(s, x_{0,1}(s),\left|x_{0,1}^{\prime}(s)\right|\right) d s, \quad t \in\left[\varepsilon^{\prime}, t_{0}-\varepsilon^{\prime}\right] .
$$

Consequently, $-x_{0,1}^{\prime \prime}(t)=\Phi(t) f\left(t, x_{0,1}(t),\left|x_{0,1}^{\prime}(t)\right|\right), \quad t \in\left(\varepsilon^{\prime}, t_{0}-\varepsilon^{\prime}\right) \cup\left(t_{0}+\varepsilon^{\prime}, 1-\varepsilon^{\prime}\right)$. Since $\varepsilon^{\prime}$ is arbitrary, we have $-x_{0,1}^{\prime \prime}(t)=\Phi(t) f\left(t, x_{0,1}(t),\left|x_{0,1}^{\prime}(t)\right|\right), t \in\left(0, t_{0}\right) \cup\left(t_{0}, 1\right)$. In addition $x_{0,1}(0)=x_{0,1}(1)=0$, and $x_{0,1}$ is a solution of $(1.1)$ with $x_{0,1}(t)>0$ on $(0,1)$.

For the set $\left\{x_{n, 2}\right\}_{n \in N_{0}} \subseteq\left(\Omega_{2}-\bar{\Omega}_{1}\right) \cap P$, a similar proof yields a convergent subsequence $\left\{x_{n_{i}, 2}\right\}$ of $\left\{x_{n, 2}\right\}$ with $\lim _{i \rightarrow+\infty} x_{n_{i}, 2}=x_{0,2} \in C^{1}[0,1]$. Also $x_{0,2}$ is a nonnegative solution of $(1.1)$ with $x_{0,2}(t)>0$ on $(0,1)$ and $R_{1}<\left\|x_{0,2}\right\|<\frac{4 R_{2}}{a^{*}\left(1-b^{*}\right)}$.

Consequently, (1.1) has at least two different nonnegative solutions $x_{0,1}$ and $x_{0,2}$ with $\left\|x_{0,1}\right\|<R_{1}<\left\|x_{0,2}\right\|$.

EXAMPLE 4.1. Consider the boundary value problems

$$
\left\{\begin{array}{l}
x^{\prime \prime}+\mu\left[1+\left|x^{\prime}\right|^{e}+\left|x^{\prime}\right|^{-a}\right]\left[y^{b}+y^{-d}+1\right]=0, \quad t \in(0,1) \\
x(0)=0, \quad x(1)=0,
\end{array}\right.
$$


with $0 \leq a, 0 \leq e<1, b>1,0<d<1$ and $\mu>0$. If

$$
\mu<\frac{1}{2+a}\left(\sup _{c \in(0,+\infty)} \frac{c}{\left[c+c^{b+1}+c^{1-d} /(1-d)\right]^{\frac{1}{2+a}}}\right)^{2+a},
$$

then (4.23) has at least two nonnegative solutions.

REMARK 4.1. Notice that (4.1)-(4.4) are only needed to guarantee the existence of $x_{0,1}$ in Theorem 4.1 .

\section{REFERENCES}

1. R. P. Agarwal, D. O'Regan and V. Lakshmikantham, Nonuniform nonresonance at the first eigenvalue for singular boundary value problems with sign changing nonlinearities, J. Math. Anal. Appl. 274 (2002), 404-423.

2. R. P. Agarwal and D. O'Regan, Existence theory for single and multiple solutions to singular positone boundary value problems, J. Differential Equations 175 (2001), 393-414.

3. A. Capielto and W. Dambrocio, Multiplicity results for some two-point superlinear asymmetric boundary value problems, Nonlinear Analysis 38 (1999), 869-896.

4. K. Coudreau, A multiplicity result for a nonlinear boundary value problem, J. Math. Anal. Appl. 218 (1998), 395-408. Inc., 1988).

5. D. Guo and V. Lakshmikantham, Nonlinear problems in abstract cones (Academic Press,

6. J. Henderson and H. B. Thompson, Existence of multiple solutions for second order boundary value problems, J. Differential Equations 166 (2000), 443-454.

7. P. Kelevedjiev, Existence of positive solutions to a singular second order boundary value problems, Nonlinear Analysis 50 (2002), 1107-1118.

8. M. Meehan and D. O'Regan, Multiple nonnegative solutions of nonlinear integral equations on compact and semi-infinite intervals, Applicable Analysis 74 (2000), 413-427. 1994).

9. D. O'Regan, Theory of singular boundary value problems (World Scientific, Singapore,

10. D. O'Regan, Existence theory for nonlinear ordinary differential equations (Kluwer Academic Publishers, 1997).

11. S. Staněk, Positive solutions of singular positone Dirichlet boundary value problems, Mathematical and Computer Modelling 33 (2001), 341-351.

12. I. Yermachenko and F. Sadyrbaev, Types of solutions and multiplicity results for twopoint nonlinear boundary value problems, Nonlinear Analysis, in press. 